\title{
El convencionalismo jurídico o la irrelevancia del juspositivismo*
}

\author{
Legal Conventionalism or the Irrelevance \\ of Legal Positivism
}

\author{
Alfonso GARCÍA FIGUEROA \\ Universidad de Castilla-La Mancha \\ AlfonsoJ.GFigueroa@uclm.es
}

Resumen: A partir de la tesis de Juan Carlos Bayón de que su «convencionalismo profundo» es el mínimo contenido del positivismo jurídico, este trabajo sostiene que el positivismo no puede ser válido ni siquiera bajo esta concepción estrecha, dadas las dificultades que presenta mantene una diferencia fuerte entre corrección y convención en el seno del constructivismo moral que subyace a la teoría jurídica del neoconstitucionalismo.

Palabras clave: positivismo jurídico; convencionalismo; neoconstitucionalismo.

\begin{abstract}
Assuming Juan Carlos Bayón's thesis that the so-called 'deep conventionalism' is the minimum content of legal positivism, this paper argues that positivism cannot be valid, even under this 'thin' conception, due to the difficulties of maintaning a strong difference between correction and convention within moral constructivism, which underlies the legal theory of neoconstitutionalism
\end{abstract}

Keywords: legal positivism; conventionalism; neoconstitutionalism.

* Agradezco las observaciones al primer borrador formuladas por Miguel Ángel Pacheco, Antonio Peña Freire y Luis Prieto. Durante el mes de mayo de 2018 sometí algunas de las ideas contenidas en este trabajo a la consideración de tres auditorios diversos. Agradezco a Manuel Escamilla su invitación a discutir una versión simplificada ante el primero de ellos, en el Palacio de la Madraza de Granada. En segundo lugar, estoy en deuda asimismo con Josep J. Moreso por su invitación a someter este paper a su seminario en la Universitat Pompeu Fabra de Barcelona. Tanto sus observaciones como la del resto de participantes, en especial las de Josep Maria Vilajosana y Lorena Ramírez Ludeña han sido especialmente útiles para mi. Finalmente, agradezco a Juan Antonio García Amado y Pablo Bonorino que aceptaran para su discusión algunas ideas de este paper en el I Encuentro Internacional sobre argumentación y conflicto de derechos en la Facultad de Derecho que la Universidad de Vigo tiene en Orense. Especialmente agradecido quedo a Javier Díaz Revorio por hacer posible la discusión del texto con Laura Clérico, cuya contraponencia al borrador original en el II Curso de Especialización en Derecho Constitucional el día 3 de julio de 2018 me ha sido de gran utilidad. Naturalmente, los errores son de mi exclusiva responsabilidad. 


\section{LA RESPUESTA CONVENCIONALISTA FRENTE A LA CRISIS EXÓGENA Y ENDÓGENA DEL POSITIVISMO JURÍDICO}

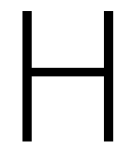
ace ya tres décadas que H.L.A. Hart ${ }^{1}$ señaló en la publicación de Los derechos en serio por Ronald Dworkin (1976) el punto final de un bicentenario de hegemonía juspositivista que había inaugurado el Fragmento sobre el Gobierno ${ }^{2}$ (1776) de Jeremy Bentham. Por su origen, cabe clasificarlas en exógenas (cuando son formuladas por los críticos del positivismo jurídico) y endógenas (cuando son formuladas en el propio seno del positivismo jurídico). Todas ellas han provocado un progresivo debilitamiento del positivismo jurídico que ha culminado con su reducción a alguna forma de convencionalismo jurídico. Según el convencionalismo jurídico, en última instancia el Derecho es el resultado de una convención y no una manifestación de corrección.

La principal tesis que desearía sostener a continuación podría resumirse así: el convencionalismo jurídico sólo puede evitar caer en la trivialidad, si caracteriza lo convencional por oposición a una filosofía moral plausible; pero como la única filosofía moral plausible es parcialmente convencional, entonces el convencionalismo no puede evitar caer en la trivialidad. Por tanto, si el convencionalismo representa, a su vez, la tesis esencial del positivismo jurídico (i.e., el mínimo común denominador de sus múltiples variedades), entonces el positivismo jurídico es esencialmente trivial y, por así decir, carece de futuro. Con todo, antes de entrar en los detalles de este argumento, es aconsejable consignar brevemente sus antecedentes.

\section{LA CRÍTICA EXÓGENA AL POSITIVISMO}

Durante su bicentenario de hegemonía, el positivismo jurídico tuvo que afrontar a lo largo del siglo XX sendas objeciones exógenas principales, formuladas a través de dos argumentos fundamentales: el argumento de la injusticia y el argumento de los principios ${ }^{3}$. El primero, que se condensa en el lema

1 Vid. Hart, H.L.A., «Law in the Perspective of Philosophy: 1776-1976», en Essays in furisprudence and Philosophy, OUP, Oxford, 1988, pp. 145-158.

2 Bentham, J., Fragmento sobre el Gobierno (1776), trad. Larios Ramos, J., Aguilar, Madrid, 1973.

3 Vid. DREIER, R., «Zur gegenwärtigen Diskussion des Verhältnisses von Recht und Moral in der Bundesrepublik Deutschland», en AlEXY, R. \& al. (ed.), Rechts und Sozialphilosophie in Deutschland heute, ARSP, cuaderno 44 (1991), pp. 55-67. 
«lex injustissima non est lex» ${ }^{4} \mathrm{y}$ se articula a través de la célebre fórmula de Radbruch, expurga los sistemas jurídicos de aquellas normas formalmente válidas, pero extremadamente injustas. El segundo, el argumento de los principios, afirma por su parte que pertenecen al Derecho no sólo las reglas identificadas more hartiano, sino también una serie de principios morales, cuya aplicación efectiva pone de manifiesto la relación conceptual necesaria entre Derecho y moral. Se trata de dos argumentos complementarios. El primero florece en tiempos de holocausto, genocidio y guerra; el segundo en tiempos de normalidad constitucional y democrática. El primero recurre a una ética de mínimos; el segundo a otra de máximos. El primero revela los excesos de la regla de reconocimiento hartiana y el segundo sus insuficiencias. En otras palabras, el primero reduce el contenido del Derecho; el segundo lo expande. Cada cual a su manera, ambos argumentos vinculan en un plano metateórico la teoría del Derecho a alguna filosofía moral. Por tanto, ambos argumentos contribuyen a convertir la filosofía del Derecho en ancilla philosophiae practicae $e^{5}$ la teoría del Derecho en una metaética atenta a las particularidades que adquiere la razón práctica en contextos institucionales ${ }^{6}$. En lo que sigue presupondré la viabilidad del argumento de la injusticia, del que me he ocupado en otro lugar ${ }^{7}$. En cuanto al argumento de los principios, cuyo reflejo más claro se halla, como

4 Vid. Peczenik, A., «Dimensiones morales del Derecho», trad. Pérez Lledó, J.A., Doxa 8 (1990), pp. 89-109, p. 104; quien a su vez toma el dictum de LuCAS, J.R., On fustice, OUP, Oxford, 1980, p. 123.

5 Esto es, una filosofía en todo caso «regional» dentro de la filosofía general. Vid. ATIENZA, M., Filosofía del Derecho y transformación social, Trotta, Madrid, 2017, p. 83, así como las observaciones críticas de GrabowsKI, A., «Is a 'Regional' Philosophy of Law Acceptable? A Comment on The Philosophy of Law as a 'Regional' Philosophy by Manuel Atienza», <https://www.academia. edu/23483127/Philolep_2015_Is_a_Regional_Philosophy_of_Law_Acceptable_A_Comment_ on_The_Philosophy_of_Law_as_a_Regional_Philosophy_by_Manuel_Atienza>, 2015 [consultado: 26/09/2018]. Una «vindicación de la naturaleza estrictamente filosófica de nuestra disciplina» nos ofrece VEGA, J., «Legal philosophy as practical philosophy», Revus, <http://revus. revues.org/3859>, 2017 [consultado: 27/09/2017]; y también PEÑA, L., Visión lógica del derecho, Plaza y Janés, Madrid, 2017.

6 Por ejemplo, Carlos Bernal contempla la filosofía del Derecho como «una disciplina filosófica similar a la metaética, pero con un objeto distinto» (BERNAL, C. (ed.), «La tesis de la doble naturaleza del Derecho de Robert Alexy», en La doble dimensión del Derecho. Autoridad y razón en la obra de Robert Alexy, Palestra, Lima, 2011, p. 8).

7 García Figueroa, A., «Injusticia extrema y validez del Derecho. Variaciones sobre un tema de Radbruch», en BLASCO, P.L. (ed. y coord.), La justicia entre la moral y el Derecho, Trotta, Madrid, 2013, pp. 21-47. La más reciente contribución al debate sobre el argumento entre nosotros se debe a PEÑa Freire, A.M., Legalidad y orden jurídico. El debate sobre la legalidad del exterminio nazi, Atelier, Barcelona, 2018. 
es sabido, en el no-positivismo principialista de Ronald Dworkin en la cultura jurídica anglófona y de Robert Alexy en la no anglófona ${ }^{8}$, cabe afirmar que su recepción en la cultura jurídica latinoamericana (lo que incluye a la latina por antonomasia, la italiana) ha provocado el desarrollo de un amplio movimiento conocido (polémicamente ${ }^{9}$ ) como neoconstitucionalismo ${ }^{10}$.

Con todo, el argumento de los principios ha mutado hasta transformarse más bien en lo que podríamos denominar «el argumento de la derrotabilidad». Según el argumento de la derrotabilidad, todas las normas (salvo quizá los principios precisamente) son derrotables, i.e. presentan un conjunto de excepciones que no podemos anticipar exhaustivamente ex ante y cuya administración exige un razonamiento práctico que confirma la vinculación del razonamiento jurídico al moral y, en consecuencia, del Derecho a la moralidad ${ }^{11}$.

Tanto el argumento de los principios como el argumento de la derrotabilidad presuponen en realidad la validez del llamado «argumento del contraste con la práctica». Por ejemplo, en el célebre caso Elmer, invocado por Dworkin para sostener el argumento de los principios, se produce un contraste entre dos imágenes del Derecho: la que nos procura el positivismo jurídico y la que nos procura la práctica del Derecho. Por tanto, según el argumento del contraste con la práctica, la práctica del Derecho no se ajusta a la imagen positivista del Derecho. En realidad, contrastar la naturaleza del Derecho en la práctica constituye una decisión metodológica de capital importancia en

8 Lo cual me indujo a elaborar en su día una tesis doctoral abordando ambas teorías conjuntamente: García Figueroa, A., Principios y positivismo jurídico. El no positivismo principialista en las teorías de Ronald Dworkin y Robert Alexy, Centro de Estudios Políticos y Constitucionales, Madrid, 1998.

9 Vid. e.g. ATIEnZa, M., Filosofía del Derecho..., cit., cap. V. Formulo una breve réplica a su aversión por la etiqueta «neoconstitucionalismo» en GARCíA FIGUEROA, A., «Neoconstitucionalismo y argumentación jurídica», Revista de la Facultad de Derecho de la Pontificia Universidad Católica del Perú, 79 (2017), pp. 9-32; aquí p. 23.

10 Para su caracterización, singularmente fiel en y por su desapego, vid. PRIETO, L., El constitucionalismo de los derechos. Ensayos de filosofía jurídica, Trotta, Madrid, 2003, cap. I.

11 De la crisis del argumento de los principios y de las razones que limitan su alcance me he ocupado en otro lugar: GARCía FiguerOA, A., «The Ubiquity of Principles. Some Critical Remarks on Robert Alexy's Exklusionstheorem», en Borowski, M.; Paulson, S.; SieckmanN, J.R. (eds.), Rechtsphilosophie und Grundrechtstheorie. Robert Alexys System, Mohr Siebeck, Tubinga, 2017, pp. 523-545. Las limitaciones del alcance del argumento de los principios pueden rastrearse en las limitaciones del argumento de la ponderación. Esta estrategia se puede apreciar en los sucesivos «deslindes» a los que Laura Clérico somete la ponderación alexiana en su trabajo CLÉRICO, L., «Examen de proporcionalidad y objeción de indeterminación», Anuario de Filosofía del Derecho, 2015 (XXXI), pp. 73-99. 
sí misma, más allá de nuestros compromisos con una ontología de las normas; pues supone vincular e incluso asimilar, como hace Dworkin, la teoría del Derecho a una «teoría de la adjudicación»; es decir a una teoría de la argumentación jurídica. Desde esta perspectiva, quizá exista ya en la propia formulación del argumento del contraste con la práctica un presupuesto que no tenemos por qué aceptar, puesto que el argumento pretende demostrar algo que su denominación cuestiona; a saber, que el significado del Derecho radica en su uso. Dicho de otro modo: no es que podamos saber cómo es el Derecho contrastándolo con la práctica. Más bien, la práctica es el Derecho si puedo decirlo así. Desde esta perspectiva, el argumento del contraste con la práctica es en sí mismo un argumento a favor del lema de «el Derecho como argumentación $\gg^{12} \mathrm{y}$ de una concepción interpretativa del Derecho superadora de una visión estática del Derecho.

\section{LA CRÍTICA ENDÓGENA AL JUSPOSITIVISMO: DE LA DEBILITACIÓN AL MINIMALISMO DEL CONVENCIONALISMO PROFUNDO}

A partir del «supuesto giro convencionalista» ${ }^{13}$ que Hart imprime a su teoría con su célebre Postscript, se produce la más sofisticada crítica endógena al positivismo, una crítica o autocrítica que ocasionó la conocida eclosión de variedades de positivismo jurídico en torno a tres posiciones, que se corresponden con la aplicación de tres operadores modales a la presencia de criterios morales en la regla de reconocimiento. Es decir, mientras el positivismo excluyente de Raz sostiene que «la determinación de aquello que el derecho es no puede depender de su adecuación a la moral crítica $\gg^{14}$; el positivismo incluyente sostendría, más débilmente, que no necesita (pero puede) depender de tal adecuación. De ahí que el positivismo inclusivo sea, a juicio de Coleman, «una teoría de las fuentes posibles de validez» ${ }^{15}$ (cursiva mía). Por su parte, el positivismo normativo o ético sostiene, en fin, que la identificación del De-

12 Especialmente alentado entre nosotros por ATIENZA, M., El Derecho como argumentación, Ariel, Barcelona, 2006.

13 AREna, F.J., El convencionalismo jurídico. Un recorrido analítico, Marcial Pons, Madrid, 2014, p. 20.

14 Vilajosana, J.M., Identificación y justificación del derecho, Marcial Pons, Madrid, 2007, pp. 77 y ss.

15 Coleman, J. L., La pratica dei principi. In difesa di un approccio pragmatista alla teoría del diritto trad. Alabiso, V.; PINO, G. (rev.), Il Mulino, Bolonia, 2006, p. 193. En todos los casos, las traducciones al castellano son mías cuando la fuente citada no sea española. 
recho no debe depender de su adecuación a la moral crítica. En lo que sigue prescindiré de esta tercera variedad de positivismo ${ }^{16}$, para concentrarme en el papel decisivo de las tesis convencionalistas en la «misión de rescate del positivismo jurídico» ${ }^{17}$ a la que nos convocaba hace ya unos años Juan Carlos Bayón en dos influyentes trabajos ${ }^{18}$ que situaban la defensa del convencionalismo jurídico en un plano teórico y también metateórico. En un plano teórico, según el convencionalismo, la identificación del Derecho obedece a una convención social. Por decirlo en las wittgensteinianas palabras de Bayón: «los límites del Derecho son los límites de nuestras convenciones». En un plano metateórico, Bayón sostiene que el convencionalismo constituye precisamente el «contenido mínimo del positivismo jurídico» (ya sea excluyente o incluyente), porque «(l)a tesis de la conexión [justificatoria, del Derecho con la moral] hace su trabajo, por así decir, una vez que el derecho ha sido ya identificado» ${ }^{19}$. Naturalmente, la tesis teórica y la metateórica se hallan entrelazadas. La «necesidad de una identificación premoral del Derecho» ${ }^{20}$ aconseja una concepción del Derecho minimalista, «fina o delgada» (thin) porque, en efecto, ello «deja que el trabajo moral sea hecho por el concepto de moralidad y no por el concepto de legalidad $\gg^{21}$. En suma, esta necesidad minimalista de una identificación premoral sería satisfecha por la tesis convencionalista, precisamente porque tal

16 Formulo en García FigueroA, A., Criaturas de la moralidad. Una aproximación neoconstitucionalista al Derecho a través de los derechos, Trotta, Madrid, 2009, pp. 182 y ss., una crítica al positivismo normativo o ético tomando como blanco tanto la versión sumisa de Tom Campbell como la antisistema de Luis Prieto. A Antonio Peña Freire le debo una observación que merece un desarrollo imposible aquí. Por expresarlo en términos que emplearé en este trabajo: La tesis de que el Derecho es una convención a su vez representa en sí misma una convicción. Ello haría del positivismo normativo la base auténtica y originaria de cualquier forma plausible de positivismo jurídico.

17 La expresión es PÉREZ Bermejo, J.M., «El convencionalismo como sucesor: noticia de una discusión en torno a la herencia del positivismo», en RAMOs PaSCUA, J.A.; Rodilla GonZález, M.A. (eds.), El positivismo jurídico a examen. Estudios en homenaje a fosé Delgado Pinto, Aquilafuente, Universidad de Salamanca, 2006, pp. 411-445.

18 BAYÓN, J.C., «El contenido mínimo del positivismo jurídico», en ZAPATERO, V. (ed.), Horizontes de la filosofía del Derecho. Homenaje a Luis García Sanmiguel (vol. 2), Servicio de Publicaciones de la Universidad de Alcalá, 2002, pp. 33-54 y, del mismo, BAYÓN, J.C., «Derecho, convencionalismo y controversia», en NAVARRO, P.E.; REDONDO, M.C. (comps.), La relevancia del derecho. Ensayos de filosofía jurídica, moral y política, Gedisa, Barcelona, 2002, pp. 68 y ss.

19 BAYÓN, J.C., «El contenido mínimo...», cit., p. 43.

20 Schauer, F., «Positivism as Pariah», en GeOrge, R.P. (ed.), The Autonomy of Law, OUP, Oxford, 1999, p. 124.

21 Schauer, F., «Positivism Through Thick and Thin», en BIX, B. (ed.), Analysing Law, OUP, Oxford, 1998, cap. 3, p. 76. «Legalidad» en el sentido de juridicidad. 
identificación es previa e independiente de la discusión sobre la vinculación o no del Derecho a la moral ${ }^{22}$. A partir de este presupuesto, Bayón desarrolla una visión personal y estimulante del convencionalismo que denomina «convencionalismo profundo».

El convencionalismo profundo presenta al menos una ventaja y un inconveniente para el positivismo tanto en el plano teórico y en el metateórico respectivamente. La ventaja metateórica consiste en que con su propuesta de un positivismo minimalista, Bayón aclara el debate mediante la eliminación en el concepto positivista del Derecho de adherencias metaéticas no deseadas. $\mathrm{El}$ inconveniente metateórico (y puramente retórico) consiste en que, identificando el contenido mínimo del positivismo, Bayón facilita a los críticos el blanco al que dirigir sus ataques. Después de todo, si el convencionalismo profundo no resistiera los embates del antipositivismo, entonces el positivismo jurídico habría perdido nada menos que su contenido mínimo y su viabilidad se vería seriamente comprometida.

La ventaja teórica consiste en que el convencionalismo responde a la intuición profundamente positivista de que el Derecho «puede tener cualquier contenido», en las célebres palabras de Kelsen. El inconveniente teórico más grave consiste en que las tesis convencionalistas corren el riesgo de caer en la banalidad, de propugnar tesis triviales o vacías. Si lo que el convencionalismo sostiene es que el Derecho es convencional, entonces la sustantividad del convencionalismo depende de que el concepto de convención resulte mínimamente interesante. Sin embargo, la concepción del criterio de identificación del Derecho como convención sólo reviste interés cuando es oponible a la moralidad. Es decir, sólo es interesante cuando se confronta con la cuestión moral que el convencionalismo profundo de Bayón pretende orillar. He aquí, me parece, un problema serio para el convencionalismo y los propios convencionalistas son muy conscientes de los riesgos de trivializar la teoría del Derecho a los que se expone el convencionalismo. Como advierte Marmor con razón, «el convencionalismo es una doctrina significativa sólo si no se mantiene para todos los ámbitos (across the board). Es significativa precisamente porque no todo es cuestión de convención social. En nuestro caso, es principalmente el contraste entre el derecho, que se pretende convencional, y la moralidad, que no lo es, que es de

22 Justo al contrario de lo que piensa Dworkin, quien considera que la evaluación moral del Derecho es un requisito previo para saber lo que el Derecho es. Vid. e.g. Dickson, J., Evaluación en la teoría del Derecho, trad. VEGA GÓMEZ, J., UNAM, México, 2006, p. 125. 
particular interés $\rangle^{23}$ (cursivas mías). A mi modo de ver, aquí reside el problema decisivo. El convencionalismo singulariza el Derecho como esencialmente convencional por oposición a una moralidad que esencialmente no lo es; pero no tenemos por qué asumir el presupuesto de que el Derecho sea puramente convencional y la moralidad puramente contraconvencional. Dicho de otro modo: el convencionalismo deviene inviable cuando advertimos que ni el Derecho es puramente convencional, ni (sobre todo) la moralidad es puramente no-convencional.

La importancia de este contraste revela que el convencionalismo sólo resulta relevante cuando presuponemos alguna teoría moral que defina el ámbito de lo no-convencional. Dicho aún de otro modo: a falta de una teoría moral, el convencionalismo deviene irrelevante. Desde este punto de vista, considerar el convencionalismo profundo como el contenido mínimo del juspositivismo, aislando el positivismo de otras tesis (la tesis de la separación, la tesis de la diferencia práctica o la tesis del pedigree) y de cuestiones metaéticas no parece fácil. Quizá porque hablar de teoría del Derecho siempre acaba siendo una forma oblicua de hablar de metaética y ello constituye de por sí un problema para el positivismo jurídico. Por otra parte, como vamos a comprobar a lo largo de este trabajo, a la hora de examinar en qué medida el Derecho sea un fenómeno convencional, es especialmente necesario precisar en qué sentido y con qué alcance hablamos de convención. De lo contrario, insisto, el propio convencionalismo corre el riesgo de resultar una teoría «poco informativa, teóricamente no interesante y filosóficamente poco iluminadora ${ }^{24}$.

En efecto, si definimos «convencional» como artificial, no natural, entonces resulta trivial sostener que el Derecho es convencional, pues todo fenómeno cultural lo es ${ }^{25}$. Si «convencional» significa entonces «social», avanzamos algo; pero no demasiado para el debate de la teoría del Derecho. Cabría afirmar que lo social se opone a lo natural en el sentido de que se refiere a hechos dependientes de estados intencionales (creencias, actitudes, deseos) que pueden ser convencionales o no convencionales. A su vez, las convenciones pueden originarse en un acuerdo o no, y en este segundo caso pueden tener por fin la coordinación o bien la cooperación o bien la constitución de una práctica.

23 Marmor, A., «Legal Convencionalism», en Coleman, J. (ed.), Hart's Postscript, OUP, Oxford, 2001, cap. 6, p. 216.

24 Celano, B. «La regola di riconoscimento è una convenzione?», Ragion Pratica, 21 (2003), pp. 347-360; aquí p. 347.

25 Vilajosana, J.M., «Una defensa el convencionalismo jurídico», Doxa, 33 (2010), p. 472. 
En consecuencia, como cabe apreciar, es perentorio determinar claramente en qué sentido y en qué dominio se habla de convenciones en Derecho. Pero antes, recordemos un caso al que poder fijar nuestras reflexiones.

\section{CONTRASTES PRÁCTICOS, POSITIVISMOS VARIOS Y CONVENCIONES PROFUNDAS}

El punto de partida de Bayón es el examen del argumento del contraste con la práctica. De acuerdo con este argumento, el positivismo jurídico estaría errado porque no refleja la práctica del Derecho. Para ilustrarlo, desearía recordar un caso al que me he referido en múltiples ocasiones ${ }^{26}$. Noara es una bebé muy enferma que morirá si no recibe urgentemente un trasplante hepático. El trasplante puede practicarse inter vivos, puesto que Noara sólo necesita un fragmento y felizmente su propia madre es idónea para ser la donante. Sin embargo, la madre de Noara es menor de edad y el artículo 4 de la Ley de trasplantes vigente prohibía a todo menor donar órganos. Mediante Auto 785/07 de 18 de octubre de 2007, la Juez del Juzgado de Primera Instancia número 17 de Sevilla autoriza entonces el trasplante mediante un argumento analógico: del mismo modo que en ciertos casos semejantes basta con interrogar (propiamente explorar) al menor para evaluar y reconocer su madurez y el valor de su asentimiento; así basta en este caso tal exploración y la verificación de la madurez de la madre de Noara para autorizar el trasplante. No es el momento de detenerse en la plausibilidad argumentativa de la decisión tal y como fue adoptada. Basta constatar que este Auto constituye una decisión contra legem que define un claro «contraste con la práctica». La norma jurídico-positiva aplicable dice claramente una cosa (prohíbe a todos los menores donar órganos) y la juez decidió claramente lo contrario (permitírselo a una menor, la madre de Noara). El caso Noara presenta así dos ventajas. En primer lugar, no cabe reconducirlo a un problema interpretativo (lo cual no excluye que podamos sostener una concepción interpretativa del Derecho al abordarlo, algo completamente distinto). En segundo lugar, muchos casos son jurídicamente difíciles porque en el fondo son moralmente difíciles, pero cuando lo que tratamos de establecer es si existe una relación entre moral y Derecho, entonces la dificultad moral de tales casos difuminará el contraste y sólo añadirá más confusión a

26 Por ejemplo, en García Figueroa, A., Criaturas de la moralidad, cit., p. 153. 
la dificultad jurídica. La utilidad del caso Noara reside precisamente en que es jurídicamente difícil porque nos resulta moralmente fácil (presumo que por lo menos la autorización del Auto es ampliamente compartida desde una perspectiva puramente moral y aún humanitaria, si se quiere). En otras palabras, el caso Noara apunta directamente al problema de la naturaleza y los límites del Derecho e ilustra idóneamente la crítica al convencionalismo que supone el argumento del contraste con la práctica ${ }^{27}$. ¿Qué explicación puede ofrecer una teoría del Derecho positivista a este fenómeno? Recorrer sumariamente las posiciones implicadas, nos permitirá recordar las tesis en juego.

i) Positivismo simple. Una primera respuesta sería confirmar simplemente que se ha incumplido el Derecho. Sin embargo, resulta difícil de admitir que el caso Noara sea simplemente un caso de incumplimiento del Derecho. Ciertamente, la juez podría haber argumentado que la madre de Noara, que también era una menor, debería poder acogerse al mismo principio (la protección del menor) que inspiró la redacción del art. 4 de la ley de trasplantes. Después de todo, ¿cabe acaso mayor agresión a la salud mental de una menor que impedirle salvar a su propia hija con un trasplante? Y, por cierto, ¿no sufrirá su bebé algún perjuicio si sobrevive ${ }^{28}$ y su madre acaba psicológicamente afectada por el shock de habérsele impedido salvar a su propia hija? En suma, el caso podría haberse constitucionalizado o principializado y haberse resuelto mediante ponderación; pero no fue ésa la estrategia seguida por la juez y a la que vamos a ceñirnos aquí. Lo que ahora interesa indicar es que, sea como fuere, equiparar el caso Noara con un caso de prevaricación no parece plausible. Incluso quien discrepara de la solución dada por la juez en su Auto, puede admitir que no era jurídicamente absurda, sino que entraba dentro del espectro de soluciones jurídicamente posibles. Quizá por ello, Juan Carlos Bayón desestima sin más este «positivismo simple».

ii) Positivismo excluyente. Una segunda respuesta, más atendible, consistiría en afirmar que la juez ha desarrollado una argumentación moral en el ejercicio de la discreción judicial que forma parte de sus competencias. Sería

27 Es de justicia consignar aquí la visión radicalmente distinta sobre el caso Noara que me objeta Luigi Ferrajoli en FERRAJOLI, L. «El constitucionalismo garantista. Entre paleo-positivismo y neo-iusnaturalismo», en FerRajoli, L. et al., Un debate sobre el constitucionalismo, Marcial Pons, Madrid, 2012, p. 360 (reedición del monográfico del número 34 de la revista Doxa).

28 Finalmente el trasplante de la madre a Noara no fue necesario cuando apareció un tercero donante (El Mundo, 6 de noviembre de 2007). 
la opción del positivismo excluyente raziano, cuando divide secamente dos órdenes de cuestiones: la validez del Derecho en los términos de la tesis de las fuentes sociales y la aplicación regida por consideraciones morales. La terminología para referir esta distinción es muy variada. Se trataría de distinguir de manera clara entre validez como pertenencia y validez como aplicabilidad (vinculatoriedad, bindingness) ${ }^{29}$ o también se podría distinguir entre juridicidad (legality raziana) y validez jurídica (legal validity raziana) ${ }^{30}$. Bulygin lo expresa de una manera ingeniosa al distinguir desde el punto de vista de cada norma su «tiempo externo» (durante el cual pertenece al ordenamiento) y su «tiempo interno» (el conjunto de ocasiones en que es aplicable aun sin pertenecer al ordenamiento $)^{31}$. La idea es que, del mismo modo que las normas de Derecho internacional privado y las disposiciones transitorias obligan a los jueces a aplicar respectivamente Derecho extranjero y Derecho histórico que no adquieren (ni en su caso recobran) validez mediante esa aplicación; así las normas morales serían aplicables sin adquirir por ello validez jurídica (pertenencia al Derecho). Sin embargo, el caso Noara no parece un caso análogo a la aplicación de una norma extranjera por medio de una norma de conexión de Derecho internacional privado, por ejemplo. El subterfugio al que acude la juez, que lo resuelve por analogía, excluye de por sí la idea de que nos hallemos ante una situación análoga a la aplicación de una norma extranjera y un convencionalista no debería desestimar las creencias de los participantes en la práctica. Sin embargo, esta asimilación a la aplicación de una norma extranjera es la que presumiblemente nos ofrecería Raz para explicar el caso Noara.

Como es sabido, la vinculación de la pertenencia a la aplicabilidad es un rasgo distintivo de la teoría de Dworkin. Él piensa, sobreponderando el argumento del contraste con la práctica, que para esclarecer el concepto de validez jurídica es necesario atender a la aplicabilidad. Lo que el Derecho dice (en la práctica) expresa lo que el Derecho es (su naturaleza). Por eso, la aplicación del Derecho acaba siendo una investigación sobre la naturaleza del Derecho. Por eso, la teoría de la adjudicación o la teoría de la argumentación es el verdadero núcleo de la teoría del Derecho. Por eso, en fin, Dworkin afirma que

29 Coleman, J., «Incorporationism, Conventionality, and the Practical Difference Thesis», en Coleman, J., Hart's Postscript, cit., cap. 4, p. 125.

30 Shapiro, S., «On Hart's Way Out», en Coleman, J. (ed.), Hart's Postscript, cit., cap. 5, p. 190.

31 Bulygin, E., «Tiempo y validez», en Alchourrón, C.E.; Bulygin, E., Análisis lógico y Derecho, CEC, Madrid, 1991, pp. 195-214. Del mismo, vid. BulYGIN, E., «Algunas consideraciones sobre los sistemas jurídicos», Doxa, 9 (1991), pp. 257-279; aquí pp. 266 y ss. 
«toda opinión judicial es una pieza de filosofía jurídica» ${ }^{32}$ y a esta «conclusión hiperbólica ${ }^{33}$ se opone Raz enérgicamente. A juicio de Raz, la interpretación no tiene por qué afectar el concepto de la práctica que se interpreta: interpretar a Hamlet no significa interpretar el concepto de $\mathrm{Hamlet}^{34}$.

Pero el positivismo excluyente de Raz no parece una alternativa satisfactoria y a favor de los planteamientos dworkinianos habla la tesis de que sólo podemos aproximarnos a la naturaleza del Derecho a través del esclarecimiento conceptual de la interpretación y la argumentación jurídicas. Las resonancias wittgensteinianas de este juicio resultan innegables, desde el preciso momento en que el significado de Derecho quede así vinculado al uso que se haga de él. Sólo podemos conocer una práctica cultural como el Derecho mediante la investigación de sus instancias de aplicación. El principal reduccionismo que evitamos mediante la adopción de esta perspectiva pragmática e interpretativa implícita en el argumento del contraste con la práctica (que, en definitiva, condiciona el significado de Derecho a su uso) afecta a aquellas teorías que conciben el Derecho como un sistema axiomático y estático de enunciados. Por ejemplo, la teoría del Derecho que late tras las contribuciones de Alchourrón y Bulygin representa un ejemplo inmejorable del reduccionismo que trata de evitar esta perspectiva. Alchourrón y Bulyigin afirman que «(s)ería un error interpretar nuestra caracterización del proceso de sistematización (...) como un intento de describir lo que los juristas efectivamente hacen; se trata más bien de una reconstrucción de algunos ideales de la ciencia jurídica» ${ }^{35}$. Así pues, por confesión propia, el modelo de Alchourrón y Bulygin no es fiel a la realidad de los sistemas jurídicos en la medida en que aspira a una «reconstrucción» de acuerdo con ciertos postulados racionales y no a una descripción de una práctica social, que es lo mínimo a lo que debería aspirar una auténtica teoría positivista del Derecho. Se trata, en efecto, de una rigurosa contribución al estudio de la lógica de los sistemas normativos, pero tras ella late un concepto de Derecho que excluye fatalmente su dimensión pragmática. Dado que es una teoría que ni siquiera se preocupa en desmentir su «contraste con la práctica», quien busque una teoría del Derecho en la sofisticada

32 Dworkin, R., Law's Empire, Harvard University Press, Cambridge (Mass.), 1986, p. 90.

33 Raz, J., «Two Views of the Nature of the Theory of Law. A Partial Comparison», en Coleman, J. (ed.), Hart's Postscript, cit., cap. 1, pp. 30 y ss.

34 Ibid., p. 35.

35 AlChOURRón, C.E.; Bulygin, E., Introducción a la metodología de las ciencias jurídicas y sociales, Marcial Pons, Buenos Aires, 2006, pp. 24 y ss.; 226. 
teoría de Alchourrón y Bulygin ${ }^{36}$, tarde o temprano sentirá la tentación de dirigirles aquellas palabras de Wittgenstein: «Te pedí un cuchillo para cortar el pan y me diste una cuchilla porque estaba más afilada ${ }^{37}$.

Significativamente, en la actualidad se viene promoviendo una concepción argumentativa del Derecho armónica con el punto de vista pragmático. Francesco Viola, por ejemplo, subraya en este mismo volumen que el núcleo de nuestra concepción del Derecho ya no lo constituye el ordenamiento jurídico tal y como lo hemos venido entendiendo tradicionalmente (el que reconstruyen Kelsen o Alchourrón y Bulygin), sino más bien lo que Viola refiere muy oportunamente como un(o) «spazio giuridico», entendiendo por tal un locus donde confluyen normas y argumentos, cuyo plural lugar de procedencia se halla fuera de los límites reconocidos por la teoría del Derecho positivista tradicional ${ }^{38}$. Ciertamente, esta réplica tiene también sus riesgos (más kripkensteinianos que wittgensteinianos) singularmente la disolución del sistema jurídico en su propia aplicación, a la que me referiré más adelante (apartado 7.i).

iii) El influjo de la crítica de Dworkin. Parece un mérito innegable de Ronald Dworkin el haber defendido la dimensión hermenéutica de la teoría del Derecho en un contexto jusfilosófico abrumadoramente analítico. Como hemos visto apenas unas líneas más arriba, su estrategia de ataque podría condensarse precisamente en la mutua implicación de dos preguntas segregadas por el divisionismo propio del positivismo jurídico, a saber: «¿qué dice el Derecho (concreto)?» y ¿qué es el Derecho (en abstracto)?». En efecto, en la teoría de Dworkin, para responder a la primera necesitamos haber respondido a la segunda de manera más o menos explícita. Y en la medida en que la aplicación de normas jurídicas involucra (de manera entimemática, cuando menos) un debate sobre la naturaleza del Derecho, cada juez se transforma en

36 Claro que la teoría de Alchourrón y Bulygin representa, antes que una teoría del Derecho, una teoría de los sistemas normativos en general que presta atención especial a los sistemas jurídicos.

37 Me atrevo a conjeturar que así lo haría Peter Hacker (HaCKER, P.M.S., «Lenguaje, juegos de lenguaje y formas de vida», trad. Gaffal, M., en Padilla, J.; GafFal, M. (eds.), Formas de vida y juegos de lenguaje, Plaza y Valdés, Madrid-México, 2013, pp. 29-60; p. 48). Él cita ese dictum de Wittgenstein (Wittgenstein's Nachlass, 120, p. 142 v.) para oponerse, por ejemplo, a la concepción de la vaguedad como algo intrínsecamente negativo cuando desde una perspectiva pragmática la vaguedad puede ser sencillamente necesaria y deseable.

38 VIOLA, F., «Il futuro del diritto», Persona y Derecho, 79 (2018, II) [en este mismo no $]$, pp. 9-36. 
un filósofo del Derecho ${ }^{39}$. Ante el caso Noara, Dworkin probablemente nos diría que la solución (autorización a una menor de donar órganos) depende de nuestra concepción del Derecho. Obviamente, esta implicación entre la interpretación que hacemos de los sistemas jurídicos y el esclarecimiento de su naturaleza emerge especialmente en los casos difíciles; pero ello no significa que se halle ausente de los fáciles. Simplemente, en estos últimos la cuestión sobre la naturaleza se obvia por razones pragmáticas. De ahí que, en efecto, Dworkin afirme que la teoría del Derecho (jurisprudence) «es la parte general de la adjudicación [aplicación, argumentación], prólogo silencioso de cualquier decisión en Derecho ${ }^{40}$ (cursivas mías). Esta tesis parece un presupuesto del argumento del contraste con la práctica, dada la decisiva relevancia que el argumento confiere al examen de la práctica del Derecho para esclarecer la naturaleza de éste.

Para comprender por qué no es «hiperbólica» la conclusión de que el aplicador del Derecho acaba siendo un filósofo del Derecho, es útil reconducirla al argumento de la derrotabilidad: que todas las normas sean derrotables, no significa que todas hayan sido derrotadas, pues el carácter disposicional de la propiedad de la derrotabilidad implica que se trata de una propiedad que sólo se manifiesta bajo ciertas condiciones (i.e., el «prólogo» se mantendrá «silencioso» en los casos fáciles). Por tanto, que los casos de derrota (excepción genuina) sean pocos en nada afecta a la propiedad de la derrotabilidad; del mismo modo que la sal no deja de ser soluble cuando se la encierra en una cámara acorazada impermeable al agua. Consecuentemente, la teoría del Derecho nunca es ajena a los juristas prácticos; pero su necesidad sólo se hace sensible (sólo se manifiesta) en los casos difíciles (que amenazan la estanqueidad de la cámara acorazada del principio de seguridad jurídica). Por otro lado, si el Derecho se manifiesta a través de la práctica y la práctica refleja lo que es el Derecho, entonces la teoría del Derecho es inescindible de una teoría de la argumentación que no es reducible a una práctica convencional, sino normativa (siempre que no incurramos en trivializaciones). La práctica del Derecho no se entiende sin una dimensión ideal, normativa, hacia la cual tal práctica del Derecho tiende por encima de meras convenciones ${ }^{41}$. El Derecho es una

39 Vid. Dworkin, R., «¿Deben nuestros jueces ser filósofos? ¿Pueden ser filósofos?», trad. GARCía Jaramillo, L., Estudios de Derecho, vol. LXIV, n. 144 (2007), pp. 14-36.

40 Dworkin, R., Law's Empire, cit., p. 90.

41 Vid. e.g. Trujillo, I.; Viola, F., What Human Rights Are Not (Or Not Only). A Negative Path to Human Rights Practice, Nova Science, Nueva York, 2016, p. xi. 
práctica interpretativa y es la interpretación la que comporta una vinculación de esa práctica con una dimensión ideal más allá de las meras convenciones. Este punto de vista será adoptado aquí.

iv) Positivismo incluyente. Como vimos, el positivismo incluyente se limita a reconocer como posible que la regla de reconocimiento se base en la moral crítica. Basta con que así se convenga, para que sea posible. Pero si la regla de reconocimiento puede ser moral, entonces se infringe la positivista «tesis de la diferencia práctica» ${ }^{42}$. Recordemos que el positivismo hartiano establecía dos elementos importantes a la hora de caracterizar la fuerza motivacional de las normas jurídicas: las normas jurídicas son razones independientes del contenido (content-independent) y además son razones perentorias, es decir, excluyen la deliberación moral. Desde este punto de vista, las normas marcan una clara «diferencia práctica» respecto del dictado de la argumentación moral. Pero si la regla de reconocimiento pudiera incorporar contenidos morales, entonces el Derecho ya no podría marcar una «diferencia práctica» que sirviera para distinguir entre Derecho y moral. Al fin y al cabo, si la regla de reconocimiento se remitiera a normas morales, entonces al juez le bastaría con decidir moralmente ${ }^{43}$. Dado que en tal escenario el Derecho se tornaría superfluo, Nino se refiere a este problema como la paradoja «de lo superfluo del derecho» ${ }^{44}$. Como veremos más adelante, esta conclusión sólo resulta necesaria bajo una concepción no constructivista de la moral (infra 7 iii) y en todo caso da la impresión de que incurre en cierta petición de principio: debemos distinguir entre Derecho y moral porque de lo contrario no podremos distinguir entre Derecho y moral. El argumento de la diferencia práctica parece, por tanto, una cláusula para garantizar la coherencia interna del positivismo y no tiene por qué ser relevante para quien no haya asumido previamente una posición positivista de partida. Es decir, el problema del positivismo inclusivo surgiría entonces de que considerar la regla de reconocimiento como una posible convención social que recurre a la moral sería contradictorio. El incorporacionismo sacrificaría gravemente la tesis positivista del pedigree, que afirma que el Derecho puede ser identificado por su origen, sin atender a contenidos ${ }^{45}$.

42 Coleman, J., «Incorporationism, Conventionality...», cit., p. 101.

43 Ibid., p. 43.

44 NinO, C.S., Derecho, moral y politica, Ariel, Barcelona, 1994, pp. 130 y ss.

45 SHAPIRO, S., «On Hart's Way Out», cit., p. 158. 
De hecho, a la luz de casos como Noara, si el Derecho es lo que convienen los participantes en esa práctica constitutiva de su regla de reconocimiento, entonces existe una disparidad entre lo que convienen en abstracto y lo que reconocen en el caso difícil concreto ${ }^{46}$. Y si admitimos que la decisión de la juez en el caso Noara es procedente, entonces la regla de reconocimiento sería, como apunta Bayón, una «convención que se autoanula» ${ }^{47}$. Esto es lo que exige del convencionalismo mayor profundidad: distinguir entre lo que dictan las convenciones en la superficie y lo que indican las convenciones profundas que nos suministran excepciones implícitas como, por ejemplo: podrán donar las menores de edad cuando sea a sus propios descendientes.

\section{RELEVANCIA Y ALCANCE DE LAS CONVENCIONES}

La tesis central del convencionalismo profundo de Bayón afirma que «los límites de las convenciones son los límites del Derecho» ${ }^{48}$. Presumiblemente, Bayón sostendría en el caso Noara que, por más que tratáramos de buscar más allá de las convenciones un elemento contra-convencional (basado en consideraciones morales objetivas), en realidad la norma sobre la que realmente se apoyó la juez para autorizar el trasplante a Noara proviene de un trasfondo profundo de nuestra práctica jurídica que nos suministraría las excepciones implícitas a la norma «prohibido a los menores donar órganos». Pero entonces surge una cuestión ulterior: ¿es posible que haya una corrección moral más allá de las convenciones profundas y que tenga su fuente en algo distinto de tales convenciones? Este es el principal problema que cabe plantear al positivismo jurídico tout court, incluyente o no; pero para ello, antes conviene recordar cuál pueda ser la relevancia de las convenciones en el Derecho. En su obra clásica, Convention, David Lewis recurre a una convención de su pueblo natal para ilustrarnos sobre el objeto de su investigación:

«En mi ciudad natal de Oberlin, Ohio, hasta muy recientemente las llamadas telefónicas de los lugareños eran interrumpidas sin aviso pasados tres minutos. Poco después de que comenzara la práctica, se formó entre los residen-

46 Vid. Marmor, A., Interpretación y teoría del Derecho, trad. Mendoza Hurtado, M., Gedisa, Barcelona, 2000, p. 21.

47 BAYÓN, J.C., «Derecho, convencionalismo...», cit., p. 57.

48 Ibid., p. 74. 
tes de Oberlin la convención de que, cuando se interrumpiera la llamada, fuera quien llamó originalmente quien volviera a llamar mientras la parte llamada esperaba. Los residentes solían someterse a esta regularidad con la expectativa de sumisión de la otra parte de la llamada. De este modo, las llamadas fueron restablecidas con facilidad para beneficio de todos los afectados. Se contó la convención a los nuevos residentes o la aprendieron por experiencia. Subsistió durante décadas o así hasta que la interrupción fue derogada ${ }^{49}$.

Pues bien, la convención surge aquí de la interacción de expectativas cruzadas típicas de la teoría de los juegos, si bien esta situación responde a un juego de coordinación y no de conflicto. En los juegos de coordinación se busca un equilibrio. Imaginemos que en Oberlin Pepe llamó a Pepa y la comunicación se cortó. Si ambos interlocutores llaman, no podrán comunicarse. Si ninguno llama, tampoco. Sólo si uno (Pepe, o bien Pepa) llama, mientras el otro (Pepa, o bien Pepe) aguarda, entonces será posible la comunicación. ¿Pero quién llama y quién espera la llamada? Esta es la coordinación que requiere el desarrollo de una convención que discrimine entre las dos soluciones potenciales y arbitrarias en este caso. En los problemas de coordinación los valores en juego son siempre iguales entre sí en cada cuadro ${ }^{50}$ :

\begin{tabular}{llcc}
\hline & & & PEPA \\
\cline { 3 - 4 } & & Llama & No llama \\
\cline { 2 - 4 } PEPE & Llama & $0,0(\mathrm{~A})$ & $1,1(\mathrm{~B})$ \\
\cline { 2 - 4 } & No llama & $1,1(\mathrm{C})$ & $0,0(\mathrm{D})$ \\
\hline
\end{tabular}

En efecto, las dos alternativas en equilibrio son $\mathrm{B}$ y $\mathrm{C}$ y en Oberlin se resolvió el problema de coordinación mediante una convención que selecciona un «focal point»: cuando se corte la comunicación, volverá a llamar quien

49 LeWIS, D., Convention. A Philosophical Study (1969), Blackwell, Oxford, 2002, p. 43 (traducción mía de este fragmento). Como es sabido, el precedente clásico es Hume, que pretendió fundar la justicia en reglas informales frente a los argumentos contractualistas de Hobbes y Locke (vid. Postema, G., «Conventions and the foundations of Law», en Postema, G., A Treatise of Legal Philosophy and General Furisprudence, Springer, 2011, cap. 11, p. 488).

50 Tomo el modelo de representación de Batifoulier, Ph.; MerChiers, J.; Urrutiaguer, D., «David Lewis et la rationalité des conventions», Revue de philosophie économique, 6 (2002), pp. 37-55. 
hubiera hecho la llamada en primer lugar (B). Aquí no es necesario recoger al detalle la definición que da Lewis de convención ${ }^{51}$, pero sí conviene retener al menos que, en su concepción, las convenciones se dan cuando casi todos los miembros de una comunidad comparten el «conocimiento común» (common knowledge) de que casi todos actúan conforme a la convención (regularidad de comportamiento) ${ }^{52}$, casi todos esperan que casi todos los demás actúen conforme a ella, casi todos tienen las mismas preferencias en las combinaciones posibles, casi todos prefieren que cualquiera actúe de conformidad con la convención a condición de que casi todos actúen conforme a la convención («condición de dependencia $»^{53}$ ), aunque preferirían actuar conforme a la convención alternativa si casi todos actuaran conforme a tal alternativa (lo cual presupone la arbitrariedad de la convención).

Bayón no se confía a Lewis a la hora de defender su convencionalismo profundo. Y no es de extrañar, si nos fijamos en el origen de la investigación lewisiana. Si atendemos brevemente al aspecto genealógico de la aportación de Lewis, descubriremos que con ella pretendía dar solución al reto planteado por Quine de que el lenguaje no podía tener su origen en un acuerdo porque el mismo acuerdo sólo podía articularse mediante un lenguaje. La respuesta de Lewis es que podemos tener convenciones sin acuerdos y así fue como él teorizó las convenciones como mecanismos que surgen espontáneamente para coordinarnos. Por ello, la explicación del origen de la práctica no parece muy relevante una vez que comprendemos cómo funcionan estos mecanismos. Se diría que la convención puede carecer de un pasado racional, pero se orienta hacia un futuro que sí lo es. En este sentido, resulta significativo constatar que el origen de una convención lewisiana puede ser muy plural. Puede ser el azar, un precedente, real o ficticio, o incluso una analogía casualmente establecida por los participantes. En ejemplo de Lewis adaptado a nuestro país: una amiga y yo vamos sin teléfono móvil por el metro de Madrid y entonces comentamos

51 Vid. la definición definitiva en LEWIS, D., Convention, cit., pp. 78 y ss.

52 Se ha cuestionado que el «conocimiento común» sea un requisito de las convenciones. Por ejemplo, siguiendo a Bayón y Binmore, Federico J. Arena considera que puede haber convenciones no sólo sin acuerdo, sino también sin «conocimiento común». Por ejemplo, podría haber una convención que se siguiera por mero hábito y sin que mediara tal conocimiento común (ARENA, F.J., El convencionalismo jurídico..., cit., pp. 108 y ss.).

53 Celano, B., «Preconvenciones: un fragmento del trasfondo», en RamíReZ LudeÑa, L.; VilaJOSANA, J.M. (eds.), Convencionalismo y derecho, Marcial Pons, Madrid, 2016, p. 37 y del mismo, Celano, B., «Consuetudine: un'analisi concettuale», Diritto e questioni pubbliche, 14 (2014), pp. $595-667$; p. 603. 
despreocupadamente un titular del periódico: según las estadísticas, quienes se pierden en la estación de Sol, suelen reencontrarse casualmente en el monumento al oso y al madroño. No bien acabamos de comentar esa anécdota, nos perdemos de vista en la estación de Sol. Ella y yo decidimos entonces, cada cual por su cuenta, dirigirnos al oso y el madroño, guiados por lo llamativo (salient) de la noticia y, en efecto, allí nos encontramos. Una convención basada en el azar de un precedente anecdótico nos ha resuelto un problema de coordinación ${ }^{54}$.

Es más: el origen de una convención podría ser abiertamente inaceptable desde un punto de vista moral, pero eso no impediría que sobreviviera a quienes le dieron origen y se emancipara de sus causas, por muy poco edificantes que fueran. Por ejemplo, en algunas partes llaman «hacer el sábado» a limpiar ese día la casa a fondo. El origen era mostrar que no se era judío. Hoy la práctica sigue viva, pero naturalmente privada de toda connotación antisemita. Por tanto, en palabras de Lewis, «la directa influencia [del origen de la convención] se desvanece en días, años o vidas ${ }^{55}$. Muy expresivamente, Lewis compara las convenciones con el fuego: «Bajo condiciones favorables, una concentración suficiente de calor lo extiende y perpetúa. La naturaleza del fuego no depende de la fuente original de calor. Las cerillas pueden ser el mejor de los encendedores, pero eso no es razón para pensar que los fuegos encendidos de otro modo sean menos fuego ${ }^{56}$. En suma, el origen de la convención importa poco y puede ser todo lo irracional que se quiera.

Intuitivamente, todo ello sugiere que la idea de convención habría de proporcionar al positivismo una cobertura teórica idónea para reconstruir la regla de reconocimiento hartiana. Después de todo, aparentemente una convención puede tener «cualquier contenido» por decirlo kelsenianamente y también cualquier origen con tal de que sirva a los fines de coordinación social. Y sin embargo, la convención de Lewis aplicada al Derecho por lo general chirría. Por un lado, como veremos (infra 7 i), quizá uno de los inconvenientes del convencionalismo radique en ignorar que esa racionalidad a la que se orienta la convención es relevante para corregir el contenido de la convención. A pesar de la posible irracionalidad de su origen, la práctica jurídica se orienta a la racionalidad porque resulta ininteligible si no es contemplada como

54 El ejemplo, cambiando los detalles geográficos, es de LEWIS, D., Convention, cit., p. 39.

55 Ibid., p. 84

56 Ibid., p. 88. 
una purposeful enterprise ${ }^{57}$. Por otro lado, resulta llamativo que cada vez que Lewis opta por estudiar convenciones de cierta relevancia jurídica, topa con «la complicación de las sanciones jurídicas ${ }^{58}$. Así, cuando Lewis se ocupa de la «convención» de conducir por el lado derecho de la calzada, él se encuentra con la siguiente «complicación»: si no conducimos por la derecha, la guardia civil nos detendrá y nos denunciará ${ }^{59}$. Así pues, la convención se caracteriza por ser un instrumento para resolver problemas de coordinación y sufre distorsiones cuando está modificada por alguna otra forma de racionalidad y también cuando se halla sometida al elemento coercitivo. Pero este elemento coercitivo es consustancial al Derecho y más en la tradición positivista ${ }^{60}$. Por eso puede resultar tentador recurrir a las convenciones limitando su alcance a aquellos ámbitos sin sanciones como el Derecho internacional ${ }^{61} \mathrm{o}$ al Derecho constitucional $^{62}$, aunque de hecho, también se haya recurrido a las convenciones en el Derecho mercantil y de torts (responsabilidad civil) ${ }^{63}$; así como para explicar la objetividad en la interpretación constitucional ${ }^{64}$ y ello sin olvidar un «convencionalismo semántico» (que sostiene que las proposiciones sobre lo que el Derecho es depende de las creencias de la gente) ${ }^{65}$. Naturalmente, la noción de convención nos interesará aquí en relación con la teoría del Derecho, en la medida en que funde la validez de las normas jurídicas ${ }^{66}$.

57 Sobre este aspecto de la teoría de Fuller, vid. PeÑa FreIRE, A., Legalidad y orden jurídico, cit., p. 67.

58 LEWIS, D., Convention, cit., p. 48.

59 Ibid., p. 44.

60 Aunque podría ser que actuáramos por convención y no por miedo a la sanción (ibid.).

61 Aunque Lewis conjetura que llamar «convención» a, por ejemplo, la III Convención de La Haya de 1907 para evitar guerras no declaradas (y por cierto incumplida sistemáticamente) puede ser un caso análogo a llamar «Podunk Municipal Street Railway» a una empresa que operaba exclusivamente con autobuses y no con trenes (LEWIS, D., «Convention: Reply to Jamieson», en LEWIS, D., Papers in Ethics and Social Philosophy, Cambridge University Press, 2000, cap. 11, p. 137).

62 Así lo propone MacAdams, R.H., The Expressive Powers of Law. Theories and Limits, Harvard University Press, Cambridge (Mass.), p. 67.

63 Vid. Postema, G., «Conventions and the foundations...», cit., p. 484.

64 Vid. ARENA, F.J., «Convenciones e interpretación constitucional», en RAMíREZ LUDEÑa, L.; VILAJOSANA, J.M. (eds.), cit., cap. VIII.

65 Vid. Postema, G., «Conventions and the foundations...», cit., p. 484. En este nivel se sitúan, por ejemplo, las reflexiones de RAMíREZ LuDEÑA, L., «Las nuevas teorías de la referencia y el convencionalismo jurídico», en RAmírez LudEÑA, L.; Vilajosana, J.M. (eds.), cit., cap. IX.

66 Postema distingue dos versiones de convencionalismo de lo que denomina «foundational convencionalism»: una positivista, hartiana y más estrecha, según la cual «el Derecho puede existir y tiene fuerza normativa sólo cuando se funda en una práctica social», y una más amplia y fulleria- 


\section{LA IDENTIFICACIÓN CONVENCIONAL DEL DERECHO}

i) La regla de reconocimiento como convención coordinativa. Considerar que la regla de reconocimiento es una convención coordinativa ${ }^{67}$ resulta muy controvertido $^{68}$ y no sólo porque el propio Lewis acabara por restar importancia a esa dimensión coordinativa ${ }^{69}$. Si la regla de reconocimiento existe como una convención orientada a resolver problemas de coordinación, es lícito preguntarse por qué razón buscamos tal coordinación. Si afirmamos que se trata de «constituir un conjunto de criterios a partir de los cuales podamos saber cuál es el derecho de una determinada sociedad $»^{70}$, parece posible seguir indagando y entonces una consideración resulta procedente: si la regla de reconocimiento es una regla en uso entre jueces, parece que ellos no se tienen a sí mismos por participantes pasivos en el desarrollo de la convención ni ciegos a sus fundamentos. Decir que adoptan la regla de reconocimiento R arbitrariamente y no cualquier otra simplemente porque todos lo hacen y así pretenden coordinarse, no parece realista ${ }^{71}$, pues olvida la dimensión normativa inherente a la función judicial, singularmente el «aspecto interno de las normas» ${ }^{72}$. Verónica

na que sostiene que «las convenciones juegan un papel crítico al constituir el Derecho, aunque contribuyen poco o nada a los criterios de validez del sistema jurídico» (POSTEMA, G., «Conventions and the foundations...», cit., p. 484). El iusnaturalismo «procedimental y tecnológico» de Fuller, «que hace posible el Derecho» también permite evaluar su bondad (vid. EsCUDERO, R., Positivismo y moral interna del derecho, Centro de Estudios Políticos y Constitucionales, Madrid, 2000, pp. 331 y ss.).

67 Shapiro, con su interpretación funcional de la regla de reconocimiento, vio en la regla de reconocimiento una convención que cumple una función de coordinación y es aquí donde se opone a Dworkin que mantiene una visión no funcional (SHAPIRO, S., «On Hart's Way Out», cit., p. 189, nota 67$)$.

68 Por ejemplo, Jorge L. Rodríguez ha expresado sus reservas a que pueda existir un fin de coordinación previo a la regla de reconocimiento que defina lo que es el Derecho (RODRíGUEZ, J.L., «La regla de reconocimiento como convención constitutiva», en RAMÍREZ LUDEÑA, L.; VILAJOSANA, J.M. (eds.), cit., cap. IV, p. 90); lo cual sería un argumento a favor de atribuir un fin constitutivo y no coordinativo a la convención que rige la regla de reconocimiento. Por otra parte, también se ha apuntado que para preservar su normatividad, la regla de reconocimiento hartiana debería considerarse más que una convención, una costumbre más propiamente (CELANO, B., «Consuetudine: un'analisi concettuale», cit., in fine).

69 Vid. PÉREZ Bermejo, J.M., cit., p. 415.

70 Como lo expresa Vilajosana, J.M., Identificación y justificación del derecho, cit., p. 47.

71 De esta objeción de Leslie Green a la falta de atención a la normatividad de la regla de reconocimiento (GREEN, L., «The Concept of Law Revisited», Michigan Law Review, 94 (1996), pp. 1687-1717; aquí p. 1687) nos da cuenta MARMOR, A., «Convenciones, razones y derecho», trad. Carrió Sampedro, A., en Ramírez Ludeña, L.; Vilajosana, J.M. (eds.), cit., p. 72.

72 Vid. Hart, H.L.A., The Concept of Law, cit., e.g. pp. 56 ss. 
Rodríguez-Blanco nos ilustra el resultado ininteligible al que nos lleva reducir ciertas prácticas a esa «razón convencional» en general, siguiendo un imaginario diálogo con el Greco (que adopta el rol de participante):

OBSERVADOR: ¿Por qué pinta a Cristo crucificado?

El GRECO: Para representar el sacrificio de Cristo.

OBSERVADOR: ¿Pero por qué quiere representar el sacrificio de Cristo?

EL GRECO: Porque todos los artistas lo hacen.

Esta respuesta resulta absurda e ininteligible. Si el diálogo continuara así:

OBSERVADOR: ¿Por qué quiere hacer lo que los demás hacen, en este caso, representar el sacrificio de Cristo?

El GRECO: Porque es la mejor manera de conocer a Dios a través del sacrificio de su Hijo

OBSERVADOR: ¿YY por qué quiere conocer a Dios? ${ }^{73}$

Entonces, concluye Rodríguez-Blanco, sería absurdo que el Greco respondiera «porque todos lo hacen» ${ }^{74}$. ¿Y si la razón para seguir una regla de reconocimiento puramente convencional no fuera sólo la preferencia por la conformidad? Esta hipótesis permite distinguir varias situaciones:

a) La primera es que sí exista un interés de los agentes plenamente coincidente en la mera coordinación (por ejemplo, es el caso de conducir por la derecha o la izquierda). En los juegos de coordinación, sólo existe una razón absoluta para la convención, a saber: el puro interés en coordinarse. Por ello, la convención puede ser puramente arbitraria. Sin embargo, reducir la regla de reconocimiento a la resolución de un mero problema de coordinación resoluble mediante decisiones puramente arbitrarias parece ignorar el «aspecto interno» de las normas que con el fenómeno de la «aceptación» introduce consideraciones normativas ${ }^{75}$.

73 Vid. RodrígueZ-Blanco, V., «Convención y normatividad: una visión escéptica», en RAMíreZ LudeÑa, L.; Vilajosana, J.M. (eds.), cit., cap. II, p. 61.

74 Ibidem.

75 Según Bruno Celano «la idea de que la regla de reconocimiento sea arbitraria parece precipitada, casi irrisoria» (CELANO, B., «La regola di riconoscimento è una convenzione?», cit., p. 351. En contra, vid. VILAJOSANA, J.M., El derecho en acción. La dimensión social de las normas jurídicas, Marcial Pons, Madrid, 2010, pp. 176 y ss. 
b) La segunda es que junto al interés en la coordinación concurran otros intereses posibles, pero secundarios, que originen un $\ll$ conflicto parcial» ${ }^{76}$. El ejemplo claro es el juego conocido como «la batalla de sexos»: Durante su luna de miel, el recién casado quiere ir al ballet. Su esposa al boxeo. Tienen intereses diversos, pero comparten el interés superior en ir juntos a cualquiera de esos dos espectáculos. El conflicto es parcial y esto demuestra que las convenciones de coordinación «no exigen una coincidencia de intereses sino sólo una preferencia por la conformidad $\gg^{77}$.

c) Pero hay una tercera opción: que exista un «conflicto radical» de intereses entre el interés en la coordinación y el interés puramente estratégico $^{78}$. En este caso, la regla de reconocimiento tendería a describir más bien un juego del tipo dilema del prisionero. Por ejemplo, la visión del Derecho que nos ofrece Laporta ${ }^{79}$ parece presuponer esta perspectiva cuando afirma que el Derecho constituye una solución a este tipo de conflicto que ilustra con el caso de dos hombres primitivos que se encuentran con un león por la sabana. Si ambos combaten juntos al león, tendrán una posibilidad alta de salvarse. Si ambos huyen, tendrán una posibilidad baja de salvarse. Si uno huye y el otro se queda; entonces el primero tendrá altísimas posibilidades de salvarse a costa de las nulas del otro. Este planteamiento puramente estratégico y hobbesiano, si se quiere, quizá dé cuenta del origen antropológico, socio-biológico del Derecho de la cooperación; pero no del elemento justificatorio en el sentido que a continuación indicaré. En otras palabras, el dilema del prisionero podría hablarnos de las causas del Derecho, pero no de sus fines y principios.

d) La cuarta posibilidad vendría a cubrir precisamente el conflicto de principios. Consistiría en reconocer que el conflicto radical del interés en la conformidad no se da propiamente con otros intereses de los agentes, sino más bien con sus principios o valores. Dicho de otro modo, es posible que surja un conflicto entre la preferencia por la conformidad (basada en el valor de la seguridad jurídica) y la corrección (basada en el valor de la justicia). A juicio de Arena, ni el conflicto radical de intereses ni lo que he llamado «conflicto de principios» «pueden ser resueltas por una convención no basada en el acuerdo» ${ }^{80}$. A mí me parece que el caso Noara expresa este conflicto radical de principios y que sólo puede ser resuelto atendiendo a la corrección. Dado que la corrección es un

76 ARENA, F.J., El convencionalismo jurídico..., cit., p. 113.

77 Ibidem.

78 Ibid., p. 114.

79 LAPORTA, F., El imperio de la ley. Una visión actual, Trotta, Madrid, 2007, pp. 46 y ss.

80 ARENA, F.J., El convencionalismo jurídico. Un recorrido analítico, cit., p. 114. 
procedimiento para discriminar cuándo ceder o no ante la preferencia por la convención (basada en el valor seguridad jurídica); entonces debemos concluir que la corrección es criterio último (pero no único y sí concurrente) en la identificación del Derecho. Como voy a indicar más adelante, tal corrección sin embargo no excluye a su vez la idea de convención, aunque se trataría de una convención parcial y con acuerdo en la medida en que asumamos, como aquí se propone, una concepción constructivista de la moralidad. Parcial porque la corrección a la que se confía la justicia bajo una teoría constructivista es parcialmente convencional y esto significa que no puede ser puramente convencional (no puede basarse sólo en moral social) y con acuerdo, porque el acuerdo es el trasunto del discurso; i.e. de la argumentación basada en razones no puramente estratégicas que caracterizan nuestras prácticas comunicativas. Es decir, el conocimiento común al que nuestras convenciones morales se orientan críticamente requiere de una transparencia que no se da entre agentes puramente reales, sino más bien entre agentes ideales o bien entre agentes reales en una situación ideal de diálogo. Sobre estos asuntos volveré más adelante.

ii) La regla de reconocimiento como convención cooperativa. Quizá para captar esa actitud activa y normativa propia del punto de vista interno adoptado por los jueces, Coleman ve en la regla de reconocimiento, más allá de una convención con fines de coordinación ${ }^{81}$, una «actividad cooperativa compartida» como pasear o pintar una casa entre dos individuos por ejemplo. Cuando paseamos, no nos limitamos a convenir con el fin de resolver un problema de coordinación; más bien actuamos juntos movidos por un fin común. Coleman adopta este concepto de Bratman ${ }^{82}$, que subraya tres aspectos de la actividad cooperativa:

a) Sintonía recíproca implícita en que cada cual actúa a la vista del comportamiento del otro en la consciencia de que el otro también actúa así.

b) Empeño en la actividad conjunta a la que sirve su sintonía recíproca.

c) Empeño en la ayuda recíproca, pues cada actor se esfuerza por sostener los esfuerzos de los otros en una acción conjunta ${ }^{83}$.

81 Frente a Marmor que mantiene que se trata de una convención constitutiva. Vid. ColEMan, J., «Incorporationism, Conventionality, and the Practical Difference Thesis», cit., p. 117.

82 Coleman (Coleman, J.L., La pratica dei principi, cit., p. 175) toma este concepto de Bratman, M.E., «Shared Cooperative Activity», Philosophical Review, 101/2 (1992), pp. 327-341; BRATMAN, M.E. «Shared Intention», Ethics, 104 (1993), pp. 97-113. Postema (PosTEMA, G., «Conventions and the foundations of Law», cit., p. 504) subraya el cambio de opinión al respecto de Coleman, quien con anterioridad había defendido el carácter coordinativo de la convención en la identificación del Derecho.

83 Coleman, J.L., La pratica dei principi, cit., p. 175. 
Este modelo parece reproducir mejor el punto de vista del juez, que es, al fin y al cabo, de quien depende la existencia de la regla de reconocimiento. Quizá exprese bien aquel aspecto cooperativo que sugería la conocida metáfora dworkiniana de la novela en cadena, donde se asimila cada juez a un novelista convocado para seguir el curso de una novela cuyos capítulos previos han sido escritos por otros novelistas. Sin embargo, Josep Maria Vilajosana subraya que existe una diferencia crucial entre la actividad cooperativa de, por ejemplo, pintar una casa e identificar el Derecho. El pintar la casa juntos no constituye la casa pintada. Pero la identificación del Derecho sí constituye el Derecho. La existencia de la casa pintada es independiente de la acción de pintarla de un modo en que no lo es el Derecho en relación con su identificación ${ }^{84}$. Optar por la consideración de la regla de reconocimiento como una regla basada en una convención constitutiva presupone, según Vilajosana, «aislar el componente constitutivo que tiene esta práctica [la identificación del Derecho por parte de los jueces como algo distinto de su aplicación] $\gg^{85}$. Esta constatación nos lleva naturalmente a la siguiente modalidad de convención relevante, la convención constitutiva.

iii) La regla de reconocimiento como convención constitutiva. Como es sabido, la circularidad de la regla de reconocimiento con la regla de adjudicación ha supuesto un problema ampliamente debatido. Si la regla de reconocimiento que identifica el Derecho es una regla en uso entre los jueces y los jueces lo son en virtud de la regla de adjudicación del Derecho, a su vez identificado por la regla de reconocimiento, entonces incurrimos en una circularidad entre reglas y autoridad. Sin embargo, como oportunamente apunta Federico Arena, el problema de la circularidad sólo es necesariamente un problema en la medida en que asumamos una postura fundacionalista (o fundamentista) que exija hallar siempre un punto arquimédico ${ }^{86}$, algo que puede evitarse adoptando, por ejemplo, una visión holista que conciba la realidad del Derecho más bien como una red; pero, en todo caso, de tal manera que la convención se presenta como un mecanismo que rompe esta circularidad ${ }^{87}$.

84 Vid. Vilajosana, J.M., El Derecho en acción, cit., p. 136.

85 Vilajosana, J.M., El derecho en acción, cit., p. 134. Como es natural, se trata de una distinción que nunca aprobaría Ronald Dworkin, tal y como vimos anteriormente.

86 ARENA, F.J., El convencionalismo jurídico. Un recorrido analítico, cit., p. 34.

87 Vid. Postema, G., «Conventions and the foundations of Law», cit., p. 485. 
Así, por ejemplo, Marmor considera que en realidad, la objeción de que los jueces no se limitan a seguir una convención porque están vinculados normativamente (no sólo coordinativa o cooperativamente, por así decir) no es procedente porque los jueces lo son en virtud de normas jurídicas que ya han sido reconocidas (constituidas) como jurídicas por la regla de reconocimiento y, por tanto, la regla de reconocimiento se debe basar en una convención que la crea previamente, una convención constitutiva de la propia práctica que llamamos Derecho y en la que los jueces se hallan $\left\langle i n m e r s o s »^{88}\right.$. En cualquier caso, para Marmor, la regla de reconocimiento no es tanto una convención orientada a resolver un problema de coordinación ${ }^{89}$, sino que debe ser reconstruida más bien como una convención constitutiva. Igual que no decimos de las reglas del ajedrez que resuelven un problema de coordinación, pues constituyen la actividad de jugar al ajedrez; así la regla de reconocimiento crea, constituye, una actividad cuyos problemas de coordinación deben, si acaso, ser posteriores a la propia convención ${ }^{90}$.

\section{7. ¿CONVENCIÓN, CONVICCIÓN O CORRECCIÓN?}

Nos encontramos ahora en mejores condiciones de abordar nuestro caso: ¿qué significa interpretar el caso Noara bajo una concepción convencionalista de la regla de reconocimiento? Si atendemos al caso Noara deberíamos distinguir si la norma que sirve de base a la decisión de autorizar el trasplante es identificable mediante una convención (la regla de reconocimiento) o bien

88 Marmor, A., «Convenciones, razones y derecho», cit., p. 87. Esto podría interpretarse como una cierta apelación a una concepción fáctica de la función judicial al estilo de Nino o realista al estilo de Hernández Marín, Sobre estos criterios fácticos para caracterizar la condición de juez como un hecho de algún modo independiente de normas, vid. ARENA, F.J., El convencionalismo jurídico. Un recorrido analítico, cit., pp. 35 y ss.

89 Marmor, A., «Legal Conventionalism», en Coleman, J. (ed.), Hart's Postscript, cit., p. 202.

90 Marmor, A., «Convenciones, razones y derecho», cit., p. 75. No es de extrañar que Jorge L. Rodríguez, cercano en este punto a la célebre posición de Eugenio Bulygin (BulYGIN, E., «Algunas consideraciones sobre los sistemas jurídicos», cit.) sobre la naturaleza conceptual o definicional (no normativa) de la regla de reconocimiento, muestre su simpatía por esta dimensión constitutiva de la regla de reconocimiento à la Marmor, aunque a cambio de ello, Rodríguez considere poco interesante el recurso a la idea de convención y se reafirme en su adhesión a la concepción de la regla de reconocimiento como una regla definicional o conceptual (RoDRÍGUEZ, J.L., «La regla de reconocimiento como convención constitutiva», cit., 109 y ss.). 
mediante una convicción (convicción personal en el ejercicio de discreción judicial $^{91}$. La razón convencional de la juez se expresaría así: «si los demás no dijesen y no hiciesen lo que hacen, yo no diría lo que digo o haría lo que hago». La convicción de la juez se expresaría en cambio así: «aunque nadie dijese lo que dice o hiciese lo que hace, yo diría lo que digo o haría lo que hago» ${ }^{92}$. ¿Convenciones profundas o convicciones profundas? Desde una perspectiva convencionalista, ésta es, por tanto, la disyuntiva a la que nos aboca un caso como Noara, si bien tal disyuntiva no es inobjetable.

i) Primera objeción a la disyuntiva convención-convicción: el problema del seguimiento de la regla (de reconocimiento). Como es sabido, Hart expresó enfáticamente su voluntad de evitar no sólo el «noble sueño» dworkiniano de la unidad de respuesta correcta, sino también la «pesadilla» ${ }^{93}$ del escepticismo ante las reglas. En efecto, definir una regla a través de sus instancias de aplicación puede llevarnos a disolver la regla en sus infinitos casos de aplicación. Se trata de la clásica interpretación por parte de Kripke del problema del seguimiento de reglas en Wittgenstein. Recordemos brevemente el argumento de Kripkenstein ${ }^{94}$. Un maestro le dice a un alumno que siga una secuencia de números: 2, 4, 6... y el niño lo hace hasta 1000, momento a partir del cual sigue la serie así: 1004, 1008, 1012... para seguir, al rebasar 2000 así: 2006, 2012, 2018... Wittgenstein nos pone en el lugar del maestro:

Le decimos: «iMira lo que has hecho!»-Él no nos entiende. Decimos: «Debías sumar dos; ¡mira cómo has empezado la serie!»-Él responde: « ¡Sí! ¿No es correcta? Pensé que debía hacerlo así» -O supón que dijese,

91 Vilajosana contrapone convención a convicción en VILAJOSANA, J.M., El derecho en acción, cit., pp. 139 y ss. y VILAJOSANA, J.M., «¿Por qué la regla de reconocimiento es una convención?», en RAMÍREZ LudEÑA, L.; VilajosANA, J.M. (eds.), cit., cap. V, pp. 119 y ss.

92 Vilajosana toma estos contrafácticos de NARVÁEZ, M., Wittgenstein y la teoría del derecho. Una senda para el convencionalismo jurídico, Marcial Pons, Madrid, 2004, p. 280 (VILAJOSANA, J.M., El derecho en acción, cit., pp. 139 s. e VILAJOSANA, J.M., «¿Por qué la regla de reconocimiento es una convención?», en RAMÍREZ LudeÑA, L.; VilajOSANA, J.M. (eds.), cit., cap. V, pp. 119 y ss.).

93 HaRT, H.L.A., «American Jurisprudence through English Eyes: The Nightmare and The Noble Dream» (1977), en Essays in Furisprudence and Philosophy, Oxford University Press, Oxford, 1983 , pp. 123 y ss.

94 Pues, en efecto, propiamente cabría hablar «del argumento de Wittgenstein según impresionó a Kripke», en palabras del propio Kripke (KRIPKE, S.A., Wittgenstein. A propósito de reglas y lenguaje privado, Tecnos, Madrid, 2006, p. 19). En las páginas 118 y ss. puede consultarse una síntesis del argumento del lenguaje privado según es reconstruido por este autor. En contra de la validez de esta interpretación de Wittgenstein, vid. e.g. MARMOR, A., Interpretación y teoría..., cit., pp. 190 y ss. 
señalando la serie: «iPero si he proseguido del mismo modo!» - De nada nos serviría decir «¿Pero es que no ves...?» caciones y ejemplos. -Pudiéramos decir quizá en tal caso: Esta persona entiende por naturaleza esa orden, con nuestras explicaciones, como nosotros entenderíamos la orden «Suma siempre 2 hasta 1000, 4 hasta 2000, 6 hasta 3000 , etc. $\gg^{95}$

Como el significado de la regla solo queda definido mediante su uso, entonces el significado de la regla se disuelve en la práctica que presuntamente debe orientar. En el $\$ 201$ de las Investigaciones filosóficas Wittgenstein nos advierte del desconcertante resultado final: «Una regla no podría determinar ningún curso de acción porque todo curso de acción puede hacerse concordar con la regla» ${ }^{96}$. Es normal que cualquier jurista quede aterrorizado ante el monstruo de Kripkenstein, cuya encarnación en la teoría del Derecho es el realismo jurídico radical.

Supongamos ahora que llega a aquella iglesia inglesa de la que nos hablaba el viejo ejemplo de Hart, un forastero de la etnia Sij cubierto con un turbante nunca visto por esas latitudes ${ }^{97}$. La regla dice que los varones debemos descubrirnos al entrar en la iglesia; pero es lícito preguntarse ante este nuevo caso (que forma parte del universo de casos de la práctica, pero cuyo resultado incidirá sobre el contenido de la práctica) si la obligación convencional de quitarse el sombrero rige en este caso. La cuestión entonces es que, para determinar la relevancia del nuevo caso, debemos desarrollar una argumentación exterior a la práctica entendida como mera convención. Es decir, la obligación jurídica hartiana no puede obedecer exclusivamente a la práctica so pena de ser «distorsionadora porque la práctica no puede generar por sí sola su esfera de deber». Por eso, tiene razón Stavropoulos cuando afirma que «la teoría de Hart fracasa como explicación de la metafísica del deber» ${ }^{98}$. Si puedo decirlo así: el caso Noara es para el art. 4 de la Ley de trasplantes, lo que el turbante para la regla que obliga a los hombres a descubrirse en la iglesia. Sólo un

95 Wittgenstein, L., Investigaciones filosóficas, trad. García Suárez, A.; Moulines, U., Crítica, Barcelona, 2002, $\$ 185$, p. 187.

96 Ibid., p. 203.

97 Vid. Stavropoulos, N., «Obligación y práctica social», trad. RamíreZ Ludeña, L., en RaMíReZ LudeÑa, L.; Vilajosana, J.M. (eds.), cit., cap. VII, p. 171. Este autor se refería a un sombrero ranchero. Modifico el ejemplo tras descartar tocados alternativos en conversación con Antonio Peña Freire.

98 StaVRopoulos, N., «Obligación y práctica social», cit., p. 175. 
razonamiento exterior a la práctica (a la convención), un razonamiento extraconvencional, puede garantizar la aplicación del Derecho.

También Den Hartogh sitúa en la deficiente concepción de la obligación jurídica del positivismo jurídica su crítica: $\ll$ Si la obligación es un tipo de hecho social, es un tipo de hecho que a menudo sólo puede establecerse mediante un argumento moral» ${ }^{99}$. A su juicio, el respeto de las expectativas mutuas que nos conducen a una convención presupone argumentos morales. Si la convención se orienta a un bien, entonces ese bien es moralmente controvertible y por tanto presupone la existencia de valores y principios subyacentes a la práctica. Que en su origen no fueran moralmente buenos no impide que luego sean justificables desde los valores a que la práctica aspira y más teniendo en cuenta las «virtudes cooperativas» que exige la participación en la práctica social ${ }^{100}$. Si lo que caracteriza una convención es que las creencias al respecto no son corregibles $^{101}$, entonces en el caso Noara asistimos posiblemente a una corrección de la convención (lo cual invalidaría la convención que devendría corregible). Ciertamente, la réplica positivista podría insistir en que no se trata de un caso de corrección de la convención como aparenta en la superficie, sino de derrotabilidad de la regla que recurre a una excepción implícita que surge de lo profundo de la convención ${ }^{102}$. En otras palabras: el razonamiento moral no sería externo, sino interno a la convención en lo profundo. Sin embargo, esto resulta artificioso cuando añadimos otros elementos de juicio. La realidad es que «(c)uanto más excavemos en la profundidad del trasfondo -nos dice Pérez Bermejo-, más difícil será defender el carácter verdaderamente convencional de los hábitos allí integrados» ${ }^{103}$. Ello nos remite a las siguientes objeciones.

ii) Segunda objeción a la disyuntiva convención-convicción. El tertium institucional del rol judicial. ¿Podemos reducir a la disyuntiva convención-convicción la deliberación de la juez del caso Noara cuando escribe su Auto? Si afirma-

99 Den Hartogh, G., Mutual Expectations. A Conventionalist Theory of Law, Kluwer, La Haya, 2002 , p. 45 .

100 Vid. Den Hartogh, G., «A conventionalist theory of obligation», Law and Philosophy, 17 (1998), pp. 351-376; aquí p. 375; del mismo, Mutual Expectations, cit., p. 59.

101 Si me separo de las convenciones gramaticales, yo he cometido un error; si todos lo hacen menos yo, el error es mío pues la convención es otra. Por tanto,«las creencias sobre hechos convencionales no pueden estar colectivamente equivocadas» (LAGERSPETZ, E., The Opposite Mirrors. An Essay on the Conventionalist Theory of Institutions, Springer, Dordrecht, 1995, 14).

102 Y que además no afectaría a la identificación del Derecho en un plano premoral (vid. RodRíGUEZ, J.L., Lógica de los sistemas jurídicos, CEPC, Madrid, 2002, p. 390).

103 PÉrez Bermejo, J.M., cit., p. 436. 
mos que decide por convención, es necesario identificar una convención coordinativa, constitutiva o cooperativa. Decir que es meramente coordinativa o cooperativa resulta delicado. Si la juez afirmara haber autorizado el trasplante simplemente porque otros lo harían o simplemente quiere cooperar con ellos, nos resultaría poco aceptable y artificioso; quizá, en efecto, ininteligible. Si la juez afirmara haber autorizado el trasplante porque a ella le parecía lo justo, su respuesta nos resultaría asimismo insatisfactoria. ¿Acaso no sería posible que la juez del caso Noara hubiera autorizado el trasplante separándose tanto de una presunta convención como de sus propias convicciones (preferencias)? Personalmente creo que esto sucede a menudo. Por eso, reducir la explicación de la identificación del Derecho a dos alternativas (convención o bien convicción) supone en realidad establecer una falsa disyuntiva, que presupone el dualismo Derecho/moral que se trata de probar.

Imaginemos que la juez del caso Noara perteneciera a una secta religiosa que prohíbe los trasplantes. Si la disyuntiva convención/convicción fuera exhaustiva, entonces la juez no habría tenido problemas a la hora de someterse a la convención expresada en el artículo 4 que prohíbe a los menores donar órganos por ser concurrente con su convicción. Su convicción religiosa coincidiría, en lo que al caso se refiere, con la convención (aquí la ley no marcaría una diferencia práctica, por cierto). $\mathrm{Si}$, por el contrario, la juez de profundas convicciones religiosas autoriza a pesar de todo el trasplante (algo perfectamente imaginable), ¿qué habría marcado la diferencia de la decisión frente a la convención legal y la convicción religiosa concurrente? Una primera respuesta podría ser que la dicotomía convención/convicción se quiebra por la existencia de un tertium: la institución de juez y lo que su rol implica.

En efecto, una explicación particularmente prometedora consiste en insistir en el papel institucional de la juez. La juez no se debate entre aplicar una convención con el propósito de alcanzar meramente una coordinación o bien sus personalísimas opiniones morales individuales. Como oportunamente subraya Postema, las «preferencias» de los funcionarios en su interacción con los ciudadanos no son simplemente personales. Se hallan mediadas por su responsabilidad profesional ${ }^{104}$. Es decir, la juez asume un papel institucional que la obliga a actuar en un sentido cooperativo bajo una «presión racional» ${ }^{105}$ para

\footnotetext{
104 SÁNCHEZ BRÍGIDO, R., «Convenciones cooperativas, regla de reconocimiento y prácticas institucionales», en RamíREZ LudeÑA, L.; VilajosAnA, J.M. (eds.), cit., cap. VI, p. 154.

105 Vid. Postema, G., «Conventions and the foundations of Law», cit., p. 492.
} 
conformarse con el resto de los jueces (de ahí que los jueces se sometan a contratos, juramentos o promesas que garantizan su vinculación institucional $\left.{ }^{106}\right)$.

Esto supone un avance en la comprensión de la identificación del Derecho, pero no es suficiente, puesto que los tertia podrían ser reconducidos a una convención. Los convencionalistas sostendrían que las convenciones tienen un trasfondo que nos proporcionarían las reglas que rigen el papel del juez así como las excepciones implícitas para un caso como Noara. De nuevo, en el cumplimiento de su deber judicial, la juez se habría limitado a someterse a la convención para identificar no sólo respuestas superficiales, sino también las respuestas profundas que nos proporciona la práctica en un análisis más minucioso, como el de Postema:

Las convenciones (...) no son puntos estáticos y fijos (...), sino más bien nudos relativamente estables en una matriz dinámica. Su significación completa no puede ser apreciada extraídas de esta matriz. Es esta matriz, a disposición de todos y a la que todo contribuyen, la que da fuerza práctica a las decisiones convencionales particulares y procuran recursos para permitir a los participantes resolver nuevas situaciones ${ }^{107}$ (como Noara, cabría añadir aquî)

iii) Tercera objeción a la dicotomía convención-convicción: la moral (crítica) puede ser convencional (en alguna medida). ¿Cuál ha sido entonces la base sobre la que ha decidido contra legem (contra conventionem) la juez del caso Noara? He aquí el error principal sobre el que a mi modo de ver se edifica el convencionalismo. Si para no ser banal, el convencionalismo tiene que plantearse a través de esta dicotomía, entonces resulta inviable. No tanto porque el Derecho no sea cosa de convenciones; sino más bien porque la moral crítica (que no es sólo cuestión de convicción, individual) también es cuestión de convenciones hasta cierto punto y eso quiebra la dicotomía de Derecho y moral, dos prácticas sociales entre las que ya no rige el puro dualismo, sino un cierto gradualismo ${ }^{108}$. En ambas prácticas hallamos elementos de corrección (presuntamente exclusiva de la moralidad) y de institucionalización (presuntamente exclusiva del Derecho). Desde este punto de vista, el problema del convencionalismo no reside tanto en una deficiente descripción de la dimensión convencional del Derecho cuanto en la falta de reconocimiento de la

\footnotetext{
106 SÁNCHEZ BRÍGIDO, R., cit., p. 162.

107 Vid. Postema, G., «Conventions and the foundations of Law», cit., p. 496.

108 Cfr. las consideraciones de PEÑA FREIRE, A. Legalidad y orden jurídico, cit., pp. 102 y ss.
} 
dimensión convencional de la moral crítica. Eerik Lagerspetz era consciente de ello cuando escribió lo siguiente:

Las normas de la moral personal o crítica ${ }^{109}$ no son convencionales (...). Si creo que comer carne está mal, tengo una razón para seguir la regla incluso si soy la única persona que tiene esa convicción. El contraste con las reglas de la gramática, etiqueta, o (algunas partes del Derecho) es obvia. (los teóricos que tienen una visión convencionalista de la moralidad pueden discrepar aqui ${ }^{110}$ (cursivas mías).

Ésa es la clave: si sea posible una moralidad crítica en alguna medida convencional. Paradójicamente, puede que un positivista sea hoy en día alguien que simplemente niegue tal posibilidad. Compárese el carácter dinámico que más arriba Postema atribuía a las convenciones jurídicas con el quietismo que atribuye Shapiro a las normas morales: «Puesto que es parte del concepto de la moralidad que la moralidad es un sistema normativo estático, las reglas de reconocimiento incluyentes deben ser reglas secundarias estáticas... fijadas desde el comienzo» ${ }^{111}$. ¿De verdad es sostenible esta visión intimista, personal y estática (i.e. carente de procedimientos e institucionalidad) de la moralidad en extremo contraste con el dinamismo convencional del Derecho? Desde luego, esta afirmación presupone una concepción de la moralidad que no es indiscutible y que seguramente nos descubre el verdadero contenido mínimo del positivismo jurídico, i.e., su visión desenfocada de la moralidad crítica como algo absoluta e intrínsecamente anti-convencional.

En realidad, la moral crítica puede ser perfectamente concebida como un fenómeno social y seguramente sea éste (por paradójico que parezca) el problema más difícil del positivismo convencionalista. Especialmente clara es la dificultad de distinguir las convenciones jurídicas de las convenciones de la moral social $^{112}$. Después de todo, las reglas de la moralidad social también pueden ser consideradas, en efecto, convencionales. Pero tampoco podemos excluir la dimensión convencional de la moral crítica. Como apunta oportunamente Pérez Bermejo en relación con el convencionalismo profundo de Bayón, «la

\footnotetext{
109 Significativamente puestas del mismo lado.

110 Lagerspetz, E., The Opposite Mirrors, cit., pp. 17 y ss.

111 ShaPIRO, S., «On Hart's Way Out», cit., p. 182.

112 Vid. RoDRÍGUEZ-Blanco, V., «Convención y normatividad: una visión escéptica», en RAMÍREZ LudEÑA, L.; Vilajosana, J.M. (eds.), cit., cap. II, cit., pp. 55 ss.
} 
equivalencia entre positivismo y convencionalismo [por parte de Bayón] se compromete identificando formas de jusnaturalismo convencionalista ${ }^{113}$. Pérez Bermejo desestima esta vía de crítica ${ }^{114}$, pero a mí me parece, sin embargo, que va en la dirección correcta si en lugar de jusnaturalismo adoptamos alguna forma de constructivismo ético ${ }^{115}$. Desde este punto de vista, la moral crítica es también convencional (o lo es en alguna medida) y ello invalida el convencionalismo que habría tratado de rescatar el positivismo a costa de condenarlo a la trivialidad. La plausibilidad del positivismo jurídico dependería entonces no tanto de la plausibilidad del convencionalismo en sí, sino de la medida en que la moralidad sea contraconvencional y probablemente la moral no sería plenamente contraconvencional si sostenemos, por ejemplo, una concepción hobbesiana de la moral como la de David Gauthier, una «moral por acuerdo» ${ }^{116}$. Ciertamente, pudiera parecer que la moralidad es singularmente contraconvencional, cuando adoptamos teorías deontológicas. Sin embargo, incluso esto es cuestionable. Si lo pensamos bien, una institución como la promesa en el fondo se fundamenta kantianamente en una racionalidad convencional. «Todos deben cumplir las promesas» es una regla moral cuya validez racional se apoya en la expectativa trascendental de que todos la cumplen y la institución se destruiría en ese plano trascendental si la gente no siguiera generalizadamente esa convención ${ }^{117}$.

iv) Cuarta objeción: el constructivismo ético, la moralidad parcialmente convencional, disuelve el dualismo convención/convicción (moral social/moral crítica).

\footnotetext{
113 PÉREZ BERMEJo, J.M., cit., p. 441.

114 Ibidem.

115 Aunque sin ignorar la inestabilidad del «antirrealismo anómalo» en que incurre a veces el constructivismo ético. Vid. e.g. sobre el caso de Habermas: LAFONT, C., «Realismo y constructivismo en la teoría moral kantiana: el ejemplo de la Ética del discurso», en Isegoría, 27 (2002), pp. 115-129.

116 Vid. GaUTHIER, D., Morals by Agreement, OUP, Oxford, 1988, p. 268.

117 Vid. RodríguEZ, J.L., «La regla de reconocimiento como convención constitutiva», cit., p. 104, quien se apoya en el argumento de CELANO, B., «La regola di riconoscimento è una convenzione?», cit., p. 353. Aquí quizá fuera necesario distinguir dos tipos de contradicciones derivadas del uso de máximas inmorales en Kant. La contradicción se da en la voluntad si la universalización de la máxima da lugar a situaciones indeseables para uno. La contradicción se da en la concepción cuando la universalización de la máxima inmoral lleva a la aniquilación de una institución, como en el caso de la promesa (vid. KorsgaArd, Ch.M., Creating the Kingdom of Ends, Cambridge University Press, Cambridge, 1996, pp. 77 y ss.). En un plano no trascendental, sino empírico parece situar el argumento Den Hartogh, G., Mutual Expectations, cit., p. 46.
} 
El siguiente paso sería comprobar si existe algún vínculo conceptual entre la moral social y la crítica. Si existiera, entonces se disolvería la diferenciación fuerte entre la convencionalidad del Derecho y la no-convencionalidad de la moral. Pues bien, el constructivismo ético es precisamente la doctrina moral que liquida la distinción absoluta entre moral social y crítica y en esa medida es la doctrina que liquida una estrategia convencionalista para explicar el Derecho. Hace ya algunos años Luis Prieto anticipaba así de condensadamente esta vía de crítica al convencionalismo: «determinar qué dice el Derecho (...) exige emprender abiertamente un razonamiento moral, el mismo razonamiento implícito en el constructivismo moral» ${ }^{118}$. A partir de ahí y si admitimos la tesis de Bayón de que el convencionalismo constituye el contenido mínimo del positivismo jurídico, entonces la conclusión resultaría obvia: el positivismo jurídico es una doctrina inviable precisamente en la medida en que las éticas constructivistas sean viables. El convencionalismo profundo de Bayón buscaba aislar la teoría del Derecho de la filosofía moral, desarrollando la identificación del Derecho en un estadio premoral donde hallar una convención, ajena a la necesidad de corrección. Sin embargo, el único modo de mantener esta premisa metodológica consiste en contraponer de manera excluyente la convencionalidad a la corrección (definida como lo no convencional). Pero cuando definimos la moral por ser no convencional, entonces estamos en cierto modo presuponiendo que no es posible delimitar la convencionalidad sin el recurso a la moral, lo cual resulta intrigante bajo una óptica positivista cuya razón de ser consiste en delimitar el Derecho frente a la moral. Por otro lado, si sostenemos que la moral es parcialmente convencional (como sostiene el constructivismo ético), entonces el planteamiento convencionalista se ve erosionado y ello es especialmente relevante cuando recordamos que el constructivismo ético es la ética subyacente a los planteamientos neoconstitucionalistas. Si adoptamos la filosofía moral de Alexy, por ejemplo, advertiremos enseguida que ahí se halla el punto esencial del debate. La moral discursiva no es una moral contraconvencional, sino más bien una moral parcialmente convencional. El constructivismo ético pre-

118 Bien es cierto que Luis Prieto (PrIETO, L., «Identificación y justificación del Derecho», Anuario de Filosofía del Derecho, tomo XXV (2008-2009), pp. 485-505; aquí p. 494) no comparte esa crítica que él formulaba más bien para llamar la atención de Vilajosana (VILAJOSANA, J.M., Identificación y justificación del Derecho, cit.) sobre la línea de crítica al convencionalismo que sigo aquí. 
senta una moral que no es ni absolutamente convencional, ni absolutamente contraconvencional; sino que se manifiesta como una moral mixta. Alexy expresa con claridad este compromiso de la ética discursiva entre relativismo y objetivismo:

(P)uede así afirmarse que el resultado del procedimiento discursivo no es ni meramente relativo ni meramente objetivo. Es relativo en la medida en que está condicionado por las particularidades de los participantes y es objetivo en la medida en que depende de reglas. De este modo la teoría del discurso evita tanto las debilidades de las teorías morales relativistas como las de las objetivistas. ${ }^{119}$

En el fondo, el procedimentalismo de la teoría del discurso implica así una juridificación de la moral que en nuestro país no ha pasado inadvertida a filósofos morales como por ejemplo Aranguren ${ }^{120}$ o Cortina ${ }^{121}$, aunque tiene sus precedentes en Kant ${ }^{122}$. Cuando el convencionalismo exhibe su sensibilidad (bien es cierto que reactiva) frente a las cuestiones morales menoscaba la inmunidad de la teoría del Derecho al debate moral, una inmunidad con la que se pretendía garantizar al positivismo jurídico su contenido mínimo. $\mathrm{Y}$ no es de extrañar. Dejando a un lado la viabilidad de esa estrategia, cuando la teoría del Derecho ubica la identificación del Derecho en un estadio premoral incurre en cierta contradicción performativa. Hacer teoría del Derecho siempre ha sido contrastar su objeto, el Derecho positivo, con lo que no lo es (sea cual fuere su denominación). Seguramente, porque para quienes estamos inmersos en estas prácticas, ellas sólo nos resultan inteligibles tomando en consideración el ideal con el que se confrontan ${ }^{123}$. En consecuencia, cuando el convencionalismo profundo desplaza la tesis de la separación entre Derecho y moral del centro de la teoría del Derecho para situar en su lugar la tesis social

119 AleXY, R., Recht, Vernunft, Diskurs, Suhrkamp, Francfort del Meno, 1995, p. 102.

$120 \mathrm{Vid}$. ARANGUREN, J.L.L., «Filosofías racionalistas. Filosofías noéticas y Kant», en GUISÁN, E. (coord.), Esplendor y miseria de la ética kantiana, Anthropos, Barcelona, 1988, pp. 26 y ss.

121 Vid. CorTiNA, A., «La moral como forma deficiente de Derecho», Doxa, 5 (1988), pp. 69-85.

${ }^{122}$ Me permito una remisión a mi trabajo GarCía FigueroA, A., «Kant y Alexy: reglas, principios y unidad del discurso práctico. Una lectura actual de la filosofía jurídica kantiana», en CASTRO, A.; Contreras, F., Llano, F.; PanEa, J.M. (eds.), A propósito de Kant. Estudios conmemorativos del bicentenario de su muerte., Innovación Lagares, Sevilla, 2003, pp. 191-210.

123 Vid., en relación con la teoría de Fuller, PEÑA FreIRE, A., Legalidad y orden jurídico, cit., pp. 94 y ss. 
o tesis de las fuentes sociales y orillar las consideraciones metaéticas en la elaboración de un concepto de Derecho, parece incurrir en una contradicción. La búsqueda de «un mínimo contenido de positivismo jurídico» se hace así a costa de distorsionar no sólo el discurso moral, sino también el discurso de la teoría del Derecho que requiere de alguna filosofía moral de contraste para determinar al menos frente a qué se opone.

v) Quinta objeción: el cuestionamiento del dualismo convención/naturaleza. El convencionalismo profundo de Bayón se remite a un trasfondo común arraigado a nuestra forma de vida. En este punto resulta de un particular interés la posición de Bruno Celano, quien halla en ciertas «preconvenciones» una base del convencionalismo profundo que viene a cuestionar precisamente el dualismo convención/naturaleza y con él el dualismo positivismo/jusnaturalismo. Precisamente porque para Celano tales preconvenciones escapan de la rígida distinción entre lo fáctico y lo normativo ${ }^{124}$, el propio dualismo positivismo/ jusnaturalismo resultaría desenfocado.

A juicio de Celano, en el trasfondo de nuestras convenciones aparecen ciertas preconvenciones que conforman nuestra forma de vida en sentido wittgensteiniano. Las preconvenciones de la forma de vida no son codificables como un sistema de reglas ${ }^{125}$, sino que se incorporan de manera imperceptible como «una segunda naturaleza» ${ }^{126}$ de manera que se convierten en habilidades, disposiciones, que se manifiestan no en un know-that, sino en un know-bow expresado en:

«(...) automatismos: espontáneos (irreflexivos), rápidos, fluidos, llevados a cabo sin esfuerzo (effortless). Y por tanto, pueden ser particularmente rígidos, mecánicos, ciegos, obtusos. Convenciones que -por usar la enésima metáfora- se hallan impresas en la carne, en el cuerpo han pasado a ser naturales como el respirar, constituyen 'una segunda naturaleza'» ${ }^{127}$.

\footnotetext{
124 Celano, B., «Preconvenciones: un fragmento del trasfondo», en RAMÍREZ LudeÑa, L.; VILAJOSANA, J.M. (eds.), cit., cap. I., pp. 48-49.

125 Éste es, por cierto, un rasgo fundamental del particularismo. Vid. CRISP, R., «Particularizing Particularism», en Hooker, B.; LitTle, M., Moral Particularism, OUP, Oxford, 2000, pp. 23 47, aquí p. 25.

126 CELANO, B., «Preconvenciones: un fragmento del trasfondo», cit., p. 36.

$127 \mathrm{Ibid}$., pp. 28 y ss.
} 
Es como cuando nadamos a crol. Sabemos de verdad nadar a crol precisamente cuando no tenemos necesidad de pensar cómo se hace ${ }^{128}$. Cuando sale sólo y lo hemos mecanizado hasta convertirlo en parte de nuestra fisiología. Los ejemplos se pueden multiplicar. Hallaríamos otro ejemplo en el cultivo y el ejercicio del «buen gusto ${ }^{129}$. Probablemente explicables con el concurso de las neurociencias, se trata de elementos preconvencionales que incorporamos $\mathrm{y}$ aplicamos de esa manera. Cuando eso sucede, «the body takes over», insiste una y otra vez Celano ${ }^{130}$. Nuestra habilidad no nace de un código, sino de la participación en una práctica que nos ha ido enseñando así cómo decidir, cómo jugar a ese juego, cómo participar en esa forma de vida. Codificar ciertas cosas no tiene sentido, tal y como nos lo recuerdan con su especial encanto aquellas memorables «Instrucciones para subir unas escaleras» de Julio Cortázar $^{131}$ : codifican lo que carece de sentido codificar.

La forma de vida bien puede referirse a nuestra forma de vida más general como seres humanos o bien a nuestra forma de vida local («la de la tribu», nos dice Celano ${ }^{132}$ ). Pues bien, como es sabido, la investigación de los principios discursivos que rigen nuestra forma de vida más general constituye el núcleo de la ética constructivista particularmente en su manifestación habermasiana y alexyana. Y ésta es la cuestión. Una espeleología desprejuiciada en la práctica jurídica acaba iluminando las mismas profundidades de la moral que el positivismo pretende excluir del estudio del Derecho. Cuando ya en su Teoría de la argumentación jurídica, Robert Alexy ubicaba en la forma de vida más general de los seres humanos ${ }^{133}$ la fundamentación de la ética discursiva, estaba diciéndonos implícitamente por qué la práctica que denominamos «Derecho» se halla inextricablemente unida a la moralidad. Todo acto de habla regulativo (y el Derecho es un conjunto de actos de habla regulativos) erige una pretensión de corrección y es la observación de esa pretensión de corrección la que, al fin y al cabo, determina una actuación como la de la juez del caso Noara.

\footnotetext{
128 Ibid., pp. 31 y ss. Celano toma el ejemplo de Casey.

129 Celano se remite al estudio de Bourdieu, P., La distinción. Criterio y bases del gusto, trad. RUIZ DE Elvira, M.C., Taurus, Madrid, 2016, $3^{\mathrm{a}}$ ed.

130 Celano, B., «Preconvenciones: un fragmento del trasfondo», cit., p. 32.

131 Vid. CoRTÁzAR, J., «Instrucciones para subir una escalera», en Historias de cronopios y famas, Alfaguara, Madrid, 2001, $12^{\mathrm{a}} \mathrm{ed}$.

132 Celano, B., «Preconvenciones: un fragmento del trasfondo», cit., p. 46.

133 ALEXY, R., «Eine diskurstheoretische Konzeption der praktischen Vernunft», en OELMÜLLER, W. (ed.), Normenbegrïndung Normendurchsetzung, Schöningh, Padeborn, 1978, pp. 22-58; ALEXY, R., Teoría de la argumentación jurídica, trad. ATIENZA, M.; EsPejo, I., CEC, Madrid, p. 306.
} 
Ello no excluye la consideración de prácticas convencionales «de la tribu». En realidad esas prácticas convencionales se reflejan en la aportación que los participantes hacen al discurso y que portan como una segunda naturaleza, preconvencional.

En consecuencia, el problema de la ausencia de diferencia práctica del Derecho, la paradoja de lo superfluo del Derecho, sólo surge si por «moral» entendemos «moral individual»o incluso «moral social»; pero no es eso lo que los juristas tienen en mente cuando aplican el Derecho español en el caso Noara. Aquí tenemos la idea clara de que aplicar el Derecho es necesariamente hacer justicia. Ello por dos razones concurrentes: la primera es que institucionalmente es así. La justicia es un valor constitucional que obliga a los jueces y que cabe articular en el marco jurídico-positivo vigente (algo perfectamente explicable dentro del positivismo inclusivo); pero incluso si no existiera ningún apoyo institucional legal ni jurídico-positivo, se impondría la segunda razón concurrente, a saber: que el Derecho incorpora conceptualmente una pretensión de corrección que se manifiesta precisamente en la argumentación. Para ello, como vemos, no es necesario renunciar a la dimensión institucional del Derecho. Sólo si nos entregamos a un fuerte dualismo como el que presupone el convencionalismo, entonces resulta inviable la vinculación de Derecho y moral.

\section{CONCLUSIÓN: LA ALTERNATIVA DEL NEOCONSTITUCIONALISMO}

Aquí me he referido sustancialmente a un debate anglófono, pero también entre nosotros el debate entre los positivistas y sus críticos se ha ido transformando, como consecuencia de cierto agotamiento teórico ${ }^{134}$, al que ha contribuido poderosamente el entorno jurídico-político (constitucionalismo y garantismo ${ }^{135}$ ), moral (constructivismo ético ${ }^{136}$ ) e incluso sociológico (el tránsito de una cultura de la autoridad a una «cultura de la justificación» ${ }^{137}$ ). A partir de la

\footnotetext{
${ }^{134}$ Vid. AtienZa, M. y J. Ruiz Manero, «Dejemos atrás el positivismo jurídico», en Isonomía 27 (octubre 2007), pp. 7-28.

135 Acerca de la influencia del garantismo sobre las visiones constitucionalistas del Derecho, cfr. FERRAJOLI, L. et al., Un debate sobre el constitucionalismo, cit.

136 Vid. NINO, C.S., El constructivismo ético, CEC, Madrid, 1989.

137 BARberis, M., Stato costituzionale, Mucchi, Módena, 2012, p. 20.
} 
consabida asunción de una cierta «mutación genética» ${ }^{138}$ operada primero en los ordenamientos jurídicos europeos de posguerra por efecto de la rematerialización de sus Constituciones (introducción de contenidos morales en forma de catálogo de derechos), la teoría del Derecho ha tendido a reducir la propia relevancia de la discusión entre positivistas y jusnaturalistas en un nuevo contexto donde asistimos a una relativización de la diferencia entre Derecho y moral que surgen de la transacción entre Derecho y moral operada por el constitucionalismo desde el lado del Derecho y por el constructivismo desde el lado de la ética. Más precisamente, el constitucionalismo ha aproximado el Derecho a la moral porque la constitucionalización implica la moralización del Derecho; y el constructivismo ético ha aproximado la moral al Derecho, porque la ética se ha hecho discursiva, procedimental, institucional y hasta cierto punto convencional. Por ello, el dualismo Derecho-moral debería ser reemplazado por un gradualismo entre Derecho y moral, que reconociera la transacción entre ambos órdenes y que nos permitiera la transición hacia un nuevo marco de discusión, que entre nosotros ya es habitual reconocer como neoconstitucionalismo.

Quizá la baza principal del convencionalismo fuera evitar ab initio el dualismo que ha enturbiado la teoría del Derecho tradicional. Ésta, al fin y al cabo, afirmaba (jusnaturalismo) o negaba (juspositivismo) las relaciones entre dos órdenes. En cierto modo, el dualismo severo Derecho/moral ha sido el error común y profundo sobre el que positivismo y jusnaturalismo han podido edificar juntos el gran edificio de su discrepancia, que llamamos «teoría del Derecho» (jurisprudence). Desde esta perspectiva, la alternativa de Bayón consiste en un monismo que ubica la identificación del Derecho en un estadio premoral, pero aquí se ha rechazado esta solución. Primero, porque no es posible separar identificación (premoral) del Derecho y argumentación (moral en última instancia). Segundo, porque el convencionalismo identifica premoralmente el Derecho, pero requiere una filosofía moral para no ser trivial, lo cual resulta contradictorio. Tercero, porque el convencionalismo estipula que el Derecho es el ámbito de lo convencional y la moral crítica el ámbito de lo contraconvencional, cuando es posible hallar elementos de corrección en las instituciones jurídicas y elementos institucionales en las éticas constructivistas. Cuarto, porque, en definitiva, el convencionalismo desenfoca el Derecho por desenfocar la moralidad, lo cual confirma a su vez que no podemos aproximarnos premoralmente al Derecho sin adulterarlo.

138 Zagrebelsky, G., El derecho dúctil, trad. GasCón, M., Trotta, Madrid, 1995, p. 33. 


\section{REFERENCIAS}

Alchourrón, C.E.; Bulygin, E., Introducción a la metodología de las ciencias jurídicas y sociales, Marcial Pons, Buenos Aires, 2006.

ALEXY, R., «Eine diskurstheoretische Konzeption der praktischen Vernunft», en OELMÜLlER, W. (ed.), Normenbegründung Normendurchsetzung, Schöningh, Padeborn, 1978, pp. 22-58.

- Recht, Vernunft, Diskurs, Suhrkamp, Francfort del Meno, 1995.

- Teoría de la argumentación jurídica, trad. AtienZA, M.; EsPejo, I., CEC, Madrid.

ArAngurEN, J.L.L., «Filosofías racionalistas. Filosofías noéticas y Kant», en GuISÁN, E. (coord.), Esplendor y miseria de la ética kantiana, Anthropos, Barcelona, 1988.

AREnA, F.J., El convencionalismo jurídico. Un recorrido analítico, Marcial Pons, Madrid, 2014.

— «Conve nciones e interpretación constitucional», en RAMÍREZ LUDEÑA, L.; VILAJOSANA, J.M. (eds.), Convencionalismo y derecho, Marcial Pons, Madrid, 2016, cap. VIII.

AtienZa, M., El Derecho como argumentación, Ariel, Barcelona, 2006.

- Filosofía del Derecho y transformación social, Trotta, Madrid, 2017.

ATIENZA, M. y J. Ruiz Manero, «Dejemos atrás el positivismo jurídico», en Isonomía 27 (octubre 2007), pp. 7-28.

Barberis, M., Stato costituzionale, Mucchi, Módena, 2012.

Batifoulier, Ph.; Merchiers, J.; Urrutiaguer, D., «David Lewis et la rationalité des conventions», Revue de philosophie économique, 6 (2002), pp. 37-55.

BAYÓN, J.C., «Derecho, convencionalismo y controversia», en NAVARRO, P.E.; REDONDO, M.C. (comps.), La relevancia del derecho. Ensayos de filosofía jurídica, moral y política, Gedisa, Barcelona, 2002.

— «El contenido mínimo del positivismo jurídico», en ZAPATERo, V. (ed.), Horizontes de la filosofía del Derecho. Homenaje a Luis García Sanmiguel (vol. 2), Servicio de Publicaciones de la Universidad de Alcalá, 2002, pp. 33-54.

Bentham, J., Fragmento sobre el Gobierno (1776), trad. Larios Ramos, J., Aguilar, Madrid, 1973.

Bernal, C. (ed.), «La tesis de la doble naturaleza del Derecho de Robert Alexy», en La doble dimensión del Derecho. Autoridad y razón en la obra de Robert Alexy, Palestra, Lima, 2011.

Bourdieu, P., La distinción. Criterio y bases del gusto, trad. RuIZ DE Elvira, M.C., Taurus, Madrid, 2016, $3^{\text {a }}$ ed.

Bratman, M.E. «Shared Intention», Ethics, 104 (1993), pp. 97-113.

— «Shared Cooperative Activity», Philosophical Review, 101/2 (1992), pp. 327-341.

Bulygin, E., «Algunas consideraciones sobre los sistemas jurídicos», Doxa, 9 (1991), pp. 257-279.

- «Tiempo y validez», en Alchourrón, C.E.; Bulygin, E., Análisis lógico y Derecho, CEC, Madrid, 1991, pp. 195-214.

Celano, B. «La regola di riconoscimento è una convenzione?», Ragion Pratica, 21 (2003), pp. 347-360. 
— «Consuetudine: un'analisi concettuale», Diritto e questioni pubbliche, 14 (2014), pp. 595-667.

— «Preconvenciones: un fragmento del trasfondo», en RAMírez LudeÑa, L.; ViLAJOSANA, J.M. (eds.), Convencionalismo y derecho, Marcial Pons, Madrid, 2016.

ClÉRICO, L.,«Examen de proporcionalidad y objeción de indeterminación», Anuario de Filosofía del Derecho, 2015 (XXXI), pp. 73-99.

Coleman, J. L., La pratica dei principi. In difesa di un approccio pragmatista alla teoría del diritto trad. Alabiso, V.; PINO, G. (rev.), Il Mulino, Bolonia, 2006.

Coleman, J., «Incorporationism, Conventionality, and the Practical Difference Thesis», en Coleman, J. (ed.), Hart's Postscript, OUP, Oxford, 2001, cap. 4.

CORTÁzAR, J., «Instrucciones para subir una escalera», en Historias de cronopios y famas, Alfaguara, Madrid, 2001, $12^{\mathrm{a}}$ ed.

Cortina, A., «La moral como forma deficiente de Derecho», Doxa, 5 (1988), pp. 6985.

CRISP, R., «Particularizing Particularism», en HoOker, B.; LiTtLe, M., Moral Particularism, OUP, Oxford, 2000, pp. 23-47.

Den Hartogh, G., «A conventionalist theory of obligation», Law and Philosophy, 17 (1998), pp. 351-376.

- Mutual Expectations. A Conventionalist Theory of Law, Kluwer, La Haya, 2002.

Dickson, J., Evaluación en la teoría del Derecho, trad. Vega Gómez, J., UNAM, México, 2006.

DREIER, R., «Zur gegenwärtigen Diskussion des Verhältnisses von Recht und Moral in der Bundesrepublik Deutschland», en ALEXY, R. \& al. (ed.), Rechts und Sozialphilosophie in Deutschland beute, ARSP, cuaderno 44 (1991), pp. 55-67.

DwOrkin, R., Law's Empire, Harvard University Press, Cambridge (Mass.), 1986.

— «¿Deben nuestros jueces ser filósofos? ¿Pueden ser filósofos?», trad. GARCía JARAMILLO, L., Estudios de Derecho, vol. LXIV, n. 144 (2007), pp. 14-36.

Escudero, R., Positivismo y moral interna del derecho, Centro de Estudios Políticos y Constitucionales, Madrid, 2000).

FERRAJOLI, L. «El constitucionalismo garantista. Entre paleo-positivismo y neo-iusnaturalismo», en FERrajoli, L. et al., Un debate sobre el constitucionalismo, Marcial Pons, Madrid, 2012.

García Figueroa, A., Principios y positivismo jurídico. El no positivismo principialista en las teorías de Ronald Dworkin y Robert Alexy, Centro de Estudios Políticos y Constitucionales, Madrid, 1998.

— «Kant y Alexy: reglas, principios y unidad del discurso práctico. Una lectura actual de la filosofía jurídica kantiana», en CASTro, A.; Contreras, F., Llano, F.; PANEA, J.M. (eds.), A propósito de Kant. Estudios conmemorativos del bicentenario de su muerte., Innovación Lagares, Sevilla, 2003, pp. 191-210.

- Criaturas de la moralidad. Una aproximación neoconstitucionalista al Derecho a través de los derechos, Trotta, Madrid, 2009.

- «Injusticia extrema y validez del Derecho. Variaciones sobre un tema de Radbruch», en BLASCO, P.L. (ed. y coord.), La justicia entre la moral y el Derecho, Trotta, Madrid, 2013. 
— «Neoconstitucionalismo y argumentación jurídica», Revista de la Facultad de Derecho de la Pontificia Universidad Católica del Perú, 79 (2017), pp. 9-32.

- «The Ubiquity of Principles. Some Critical Remarks on Robert Alexy's Exklusionstheorem», en Borowski, M.; Paulson, S.; Sieckmann, J.R. (eds.), Rechtsphilosophie und Grundrechtstheorie. Robert Alexys System, Mohr Siebeck, Tubinga, 2017, pp. 523-545.

GaUTHIER, D., Morals by Agreement, OUP, Oxford, 1988.

GrabowsKi, A., «Is a 'Regional' Philosophy of Law Acceptable? A Comment on The Philosophy of Law as a 'Regional' Philosophy by Manuel Atienza», <https://www. academia.edu/23483127/Philolep_2015_Is_a_Regional_Philosophy_of_Law_ Acceptable_A_Comment_on_The_Philosophy_of_Law_as_a_Regional_Philosophy_by_Manuel_Atienza>, 2015 [consultado: 26/09/2018]

GreEn, L., «The Concept of Law Revisited», Michigan Law Review, 94 (1996), pp. 1687 1717.

HaCKer, P.M.S., «Lenguaje, juegos de lenguaje y formas de vida», trad. GAFFaL, M., en Padilla, J.; Gaffal, M. (eds.), Formas de vida y juegos de lenguaje, Plaza y Valdés, Madrid-México, 2013, pp. 29-60

HART, H.L.A., «American Jurisprudence through English Eyes: The Nightmare and The Noble Dream» (1977), en Essays in furisprudence and Philosophy, Oxford University Press, Oxford, 1983.

— «Law in the Perspective of Philosophy: 1776-1976», en Essays in Furisprudence and Philosophy, OUP, Oxford, 1988.

Korsgaard, Ch.M., Creating the Kingdom of Ends, Cambridge University Press, Cambridge, 1996.

KRIPKE, S.A., Wittgenstein. A propósito de reglas y lenguaje privado, Tecnos, Madrid, 2006).

LAFONT, C., «Realismo y constructivismo en la teoría moral kantiana: el ejemplo de la Ética del discurso», en Isegoría, 27 (2002), pp. 115-129.

Lagerspetz, E., The Opposite Mirrors. An Essay on the Conventionalist Theory of Institutions, Springer, Dordrecht, 1995.

LAPORTA, F., El imperio de la ley. Una visión actual, Trotta, Madrid, 2007.

LEWIS, D., Convention. A Philosophical Study (1969), Blackwell, Oxford, 2002.

- «Convention: Reply to Jamieson», en LewIs, D., Papers in Ethics and Social Philosophy, Cambridge University Press, 2000, cap. 11.

MacAdams, R.H., The Expressive Powers of Law. Theories and Limits, Harvard University Press, Cambridge (Mass.).

Marmor, A., Interpretación y teoría del Derecho, trad. Mendoza Hurtado, M., Gedisa, Barcelona, 2000.

- «Legal Convencionalism», en Coleman, J. (ed.), Hart's Postscript, OUP, Oxford, 2001, cap. 6 .

- «Convenciones, razones y derecho», trad. CARrió SAMPEDro, A., en RAMÍREZ LUDEÑa, L.; Vilajosana, J.M. (eds.), Convencionalismo y derecho, Marcial Pons, Madrid, 2016.

NARVÁEZ, M., Wittgenstein y la teoría del derecho. Una senda para el convencionalismo jurídico, Marcial Pons, Madrid, 2004. 
Nino, C.S., El constructivismo ético, CEC, Madrid, 1989.

- Derecho, moral y política, Ariel, Barcelona, 1994.

Peczenik, A., «Dimensiones morales del Derecho», trad. PÉrez Lledó, J.A., Doxa 8 (1990), pp. 89-109.

PEÑA, L., Visión lógica del derecho, Plaza y Janés, Madrid, 2017.

PeÑa Freire, A.M., Legalidad y orden jurídico. El debate sobre la legalidad del exterminio nazi, Atelier, Barcelona, 2018.

PÉREZ BERMEJO, J.M., «El convencionalismo como sucesor: noticia de una discusión en torno a la herencia del positivismo», en RAMOS PASCUA, J.A.; Rodilla GONZÁLEZ, M.A. (eds.), El positivismo jurídico a examen. Estudios en homenaje a Fosé Delgado Pinto, Aquilafuente, Universidad de Salamanca, 2006, pp. 411-445.

Postema, G., «Conventions and the foundations of Law», en Postema, G., A Treatise of Legal Philosophy and General furisprudence, Springer, 2011, cap. 11.

PRIETO, L., El constitucionalismo de los derechos. Ensayos de filosofía jurídica, Trotta, Madrid, 2003, cap. I.

- «Identificación y justificación del Derecho», Anuario de Filosofía del Derecho, tomo XXV (2008-2009), pp. 485-505.

RAMÍREZ LUDEÑA, L., «Las nuevas teorías de la referencia y el convencionalismo jurídico», en Ramírez Ludeña, L.; Vilajosana, J.M. (eds.), Convencionalismo y derecho, Marcial Pons, Madrid, 2016, cap. IX.

RaZ, J., «Two Views of the Nature of the Theory of Law. A Partial Comparison», en Coleman, J. (ed.), Hart's Postscript, OUP, Oxford, 2001, cap. 1.

RodrígueZ, J.L., Lógica de los sistemas jurídicos, CEPC, Madrid, 2002.

- «La regla de reconocimiento como convención constitutiva», en RAMÍREZ LUDEÑA, L.; Vilajosana, J.M. (eds.), Convencionalismo y derecho, Marcial Pons, Madrid, 2016, cap. IV.

RODRÍGUEZ-BLANCO, V., «Convención y normatividad: una visión escéptica», en RAMÍREZ Ludeña, L.; Vilajosana, J.M. (eds.), Convencionalismo y derecho, Marcial Pons, Madrid, 2016., cap. II.

SÁNCHEZ BRÍGIDO, R., «Convenciones cooperativas, regla de reconocimiento y prácticas institucionales», en RAmíREZ Ludeña, L.; Vilajosana, J.M. (eds.), Convencionalismo $y$ derecho, Marcial Pons, Madrid, 2016, cap. VI.

SCHAUER, F., «Positivism as Pariah», en GEORGE, R.P. (ed.), The Autonomy of Law, OUP, Oxford.

- «Positivism Through Thick and Thin», en Bix, B. (ed.), Analysing Law, OUP, Oxford, 1998, cap. 3.

ShapIro, S., «On Hart's Way Out», en Coleman, J. (ed.), Hart's Postscript, OUP, Oxford, 2001, cap. 5 .

Stavropoulos, N., «Obligación y práctica social», trad. Ramírez LudeÑa, L., en Ramírez Ludeña, L.; Vilajosana, J.M. (eds.), Convencionalismo y derecho, Marcial Pons, Madrid, 2016, cap. VII.

Trujillo, I.; Viola, F., What Human Rights Are Not (Or Not Only). A Negative Path to Human Rights Practice, Nova Science, Nueva York, 2016. 


\section{ALFONSO GARCÍA FIGUEROA}

VEGA, J., «Legal philosophy as practical philosophy», Revus, <http://revus.revues. org/3859>, 2017 [consultado: 27/09/2017].

Vilajosana, J.M., Identificación y justificación del derecho, Marcial Pons, Madrid, 2007.

- El derecho en acción. La dimensión social de las normas jurídicas, Marcial Pons, Madrid, 2010.

— «Una defensa el convencionalismo jurídico», Doxa, 33 (2010).

- «¿Por qué la regla de reconocimiento es una convención?», en RAMÍREZ LUDEÑA, L.; Vilajosana, J.M. (eds.), Convencionalismo y derecho, Marcial Pons, Madrid, 2016, cap. V.

Wittgenstein, L., Investigaciones filosóficas, trad. García SuÁrez, A.; Moulines, U., Crítica, Barcelona, 2002.

Zagrebelsky, G., El derecho dúctil, trad. Gascón, M., Trotta, Madrid, 1995. 